OPEN ACCESS

Edited by:

Federica Montagnese, Hospital of the University of

Munich, Germany

Reviewed by:

Giovanni Meola

University of Milan, Italy

Cornelia Kornblum

University Hospital Bonn, Germany

*Correspondence:

Gabriele Siciliano

g.siciliano@med.unipi.it

Specialty section:

This article was submitted to Neuromuscular Diseases,

a section of the journal

Frontiers in Neurology

Received: 13 April 2020

Accepted: 28 May 2020

Published: 07 October 2020

Citation:

Simoncini C, Spadoni G, Lai E, Santoni L, Angelini C, Ricci $G$ and Siciliano G (2020) Central Nervous

System Involvement as Outcome Measure for Clinical Trials Efficacy in

Myotonic Dystrophy Type 1

Front. Neurol. 11:624

doi: 10.3389/fneur.2020.00624

\section{Central Nervous System Involvement as Outcome Measure for Clinical Trials Efficacy in Myotonic Dystrophy Type 1}

\section{Costanza Simoncini ${ }^{1}$, Giulia Spadoni ${ }^{1}$, Elisa Lai ${ }^{1}$, Lorenza Santoni ${ }^{1}$, Corrado Angelini ${ }^{2}$, Giulia Ricci ${ }^{1}$ and Gabriele Siciliano ${ }^{1 *}$}

${ }^{1}$ Department of Clinical and Experimental Medicine, University of Pisa, Pisa, Italy, ${ }^{2}$ IRCCS S. Camillo Hospital, Venice, Italy

Increasing evidences indicate that in Myotonic Dystrophy type 1 (DM1 or Steinert disease), an autosomal dominant multisystem disorder caused by a (CTG)n expansion in DMPK gene on chromosome 19q13. 3, is the most common form of inherited muscular dystrophy in adult patients with a global prevalence of 1/8000, and involvement of the central nervous system can be included within the core clinical manifestations of the disease. Variable in its severity and progression rate over time, likely due to the underlying causative molecular mechanisms; this component of the clinical picture presents with high heterogeneity involving cognitive and behavioral alterations, but also sensory-motor neural integration, and in any case, significantly contributing to the disease burden projected to either specific functional neuropsychological domains or quality of life as a whole. Principle manifestations include alterations of the frontal lobe function, which is more prominent in patients with an early onset, such as in congenital and childhood onset forms, here associated with severe intellectual disabilities, speech and language delay and reduced IQ-values, while in adult onset DM1 cognitive and neuropsychological findings are usually not so severe. Different methods to assess central nervous system involvement in DM1 have then recently been developed, these ranging from more classical psychometric and cognitive functional instruments to sophisticated psycophysic, neurophysiologic and especially computerized neuroimaging techniques, in order to better characterize this disease component, at the same time underlining the opportunity to consider it a suitable marker on which measuring putative effectiveness of therapeutic interventions. This is the reason why, as outlined in the conclusive section of this review, the Authors are lead to wonder, perhaps in a provocative and even paradoxical way to arise the question, whether or not the myologist, by now the popular figure in charge to care of a patient with the DM1, needs to remain himself a neurologist to better appreciate, evaluate and speculate on this important aspect of Steinert disease.

Keywords: myotonic dystrophy type 1, central nervous system, clinical trials, neuropsychological outcome measures, neuroimaging 


\section{INTRODUCTION: THE COMPLEXITY OF A DISEASE}

Myotonic dystrophy type 1 (Steinert disease) is an inherited, slowly progressive, autosomal dominant disorder, representing one of the most common neuromuscular diseases with a frequency variable in different geographical areas, of 1-20 per 100,000 inhabitants $(1,2)$.

The genetic defect consists in an abnormal dynamic repetition of the unstable trinucleotide triplet CTG (cytosine-thymineguanine) at the level of the 3 'untranslated region of the $D M P K$ gene located on the long arm of chromosome 19, in locus $13.3(3,4)$.

The DMPK gene encodes for the DMPK (Myotonic Dystrophy Protein Kinase), a serine-threonine kinase with analogies to adenosine monophosphate (cAMP) dependent protein kinases undergoing self-phosphorylation, unlike other protein kinases, this is unable to phosphorylate other membrane proteins. DMPK haploinsufficiency ensues in increased myosin phosphatase phosphorylation, this inhibits its control on phosphorylated myosin levels, the latter which is responsible for increased calcium sensitivity of smooth muscle cells and alterations in the cytoskeleton of non-muscle cells $(5,6)$.

However, a more general RNA-mediated disease model underlies, as for other hereditary disorders caused by noncoding microsatellite expansions, DM1 molecular pathogenesis. Myotonic dystrophy type 1 is in fact a multisystem disease with a wide intra and inter-individual variability. The symptoms of DM1 can occur at any time of life, from child to adulthood. Patients can have a completely asymptomatic course or present severe phenotype. The wide intra and inter-individual variability observed in this disease is mainly related to the molecular mechanism underlying the pathology, i.e., to the mutational instability of the CTG expansion, which increases in subsequent generations (anticipation phenomenon, which is directly related to the severity of the symptoms and inversely related to the age of onset of the disease) and in the somatic tissues (with different expansion in different tissues and between the various patients) (7).

According to such a model, the numerous and different clinical manifestations in DM1 are determined by a reversion, in adult tissues, to fetal RNA processing patterns due to the increased expression of toxic CUG RNA expansions (8). The etiopathogenetic hypothesis most accredited to explain at the same time multisystem and high heterogeneity of DM1 is that of toxic RNA ("RNA toxic gain of function"). The genetic defect underlying the disease is the abnormal expansion of the CTG microsatellite triplet that is located at the intronic $3^{\prime}$ non-coding sequence of the DMPK gene, this resulting in the formation of expanded untranslated CUG RNA transcripts which accumulate in nuclear foci sequestering muscleblind-like (MBNL) proteins and blocking their splicing activity. Therefore, a loss of function of MBNL in DM1 affected tissues occur and more notably a splicing dysregulation of specific MBNL-targeted transcripts with a shift from adult to fetal splicing events for some tissue-specific disease manifestations such as myotonia and insulin resistance $(9-12)$. On the other hand, protein kinase C activation determines increased levels of hyperphosphorylated CUGBP1/ETR3-like factor 1 (CELF1), in affected tissues this inducing with a gain of function mechanism is a reversion to fetal isoforms of targeted proteins in adult DM1 tissues (13). Some more ancillary molecular pathogenic mechanisms are even hypothesized, for instance, the so-called "myomiRs," a group of non-muscular miRNA playing a role in muscle maintenance and myogenesis, which is also expressed in the brain. Till date, no specific association with the central nervous system involvement has been reported (14). All of these molecular mechanisms can then account for a number of downstream altered molecular pathways, these in turn are responsible of the multiplicity of clinical manifestations of the disease, the knowledge of which can be useful to increase the therapeutic army in addition to the gold standard genetic therapy. This is the case, for instance, of the reported alterations of the cell redox balance and the attempts to treat the ensuing oxidative stress with antioxidant therapies like cysteine dietary donors $(15,16)$.

However, it is not fully known how the toxic RNA hypothesis leads to the involvement of the central nervous system (CNS). From the neuropathological point of view, the presence of neuronal loss and neurofibrillary aggregates was found in patients with DM1. These characteristics, also present in other neurodegenerative diseases such as Alzheimer's disease, led to hypothesize an altered splicing of the tau protein in patients with DM1 which could explain the accumulation of neurofibrillary plaques. However, an alteration of neurodevelopment has also been hypothesized, which could account for the cognitive behavioral alterations of congenital forms (11, 17-19). On the other hand, from a therapeutic point of view, similarly to skeletal muscle involvement, multiple molecular pathways can be considered in trying to explain alterations of CNS in DM1, this is important in view of clinical trials that should consider this in their targeted objectives and the modifications of the CNS related aspects.

During the years, various clinical classifications of disease have been proposed and in particular the clinical spectrum has been divided into three forms on the basis of severity (moderate, classical and severe) and in five clinical categories based on the age at onset of symptoms (congenital, infantile, juvenile, adult and late-onset form). However, to date there is still no general consensus on the clinical classification of type 1 myotonic dystrophy (20).

\section{Multisystem Involvement}

In considering the aim of this review it seems important to address the specific topic of CNS involvement and give some brief details on other relevant clinical aspects that can interfere with CNS function in a patient with Steinert disease.

Muscular impairment: in DM1 patients, muscular impairment is characterized by asymmetrically muscle weakness and atrophy, especially in distal regions of limbs, myotonia and central and peripheral fatigue (21). Early involvement of the face and anterior neck muscles are common (2, 22). Myotonia is one of the cardinal symptoms and is characterized by delayed relaxation (prolonged contraction) of the skeletal muscles after voluntary contraction. Fatigue, described as extreme tiredness 
resulting from mental or physical exertion or illness, is common, and early symptoms in DM1 seems not to correlate with the progression of muscle weakness (23). Muscle MRI studies revealed more fat infiltration in muscles of patients with DM1 than in unaffected controls, especially in gastrocnemius medialis, soleus and tibialis anterior (24). Recently Solbakken and colleagues showed higher levels of fat infiltration and reduced muscle size in Trunk muscles of DM1 patients with correlations between MRI pictures and deficit in motor performance and respiratory function (25).

Respiratory involvement: Pulmonary complications are the leading cause of death in DM1 patients (26). Patients with DM1 tend to exhibit earlier respiratory insufficiency than patients with other neuromuscular diseases $(27,28)$. Clinicians must monitor issues such as recurrent pneumonia at baseline and serially, with pulmonary function tests. Being a relatively slow progressive disorder, respiratory involvement frequently presents itself with symptoms such as fatigue, excessive daytime sleepiness, sleep disorders (obstructive or CNS mediated sleep apnea); thereafter, clinical manifestations progress to an ineffective cough, respiratory insufficiency (restrictive ventilatory pattern), and recurrent pulmonary infections $(26,29)$. Many mechanisms are involved to explain respiratory insufficiency in DM1 besides respiratory muscle weakness and chest mechanics, and among those alterations are neural respiratory drive and abnormal central respiratory control (central hypoventilation) (30). A periodic respiratory assessment is recommended with evaluation of pulmonary function on initial assessment, with a pulmonary service referral to assess the need of receiving support for secretion management, non-invasive or invasive ventilation (31).

Cardiovascular involvement: Cardiac manifestations are among the most common manifestation of DM1. It can be present in many different forms ranging from dilative cardiomyopathy leading to terminal heart failure, rhythm disturbances, conduction abnormalities, myocardial abnormalities (cardiac non ischemic fibrosis and fatty infiltration), secondary valve insufficiencies. these cardiac abnormalities are potentially life threatening (32). Palpitations, chest pain, dyspnea, orthopnea, lightheadedness, and syncope are common symptoms requiring cardiac investigation, even if sometimes significant cardiac involvement is asymptomatic. These features are the second life-threatening manifestation of DM1 with up to $30 \%$ of death in DM1 due to cardiac causes, of which one third are sudden cardiac death as results of conduction block or ventricular tachyarrhythmia $(33,34)$.

As other disease manifestation, there is a direct correlation between CTG length and cardiorespiratory involvement: longer CTG expansion is associated with arrhythmias as well as PR and QRS prolongation, with lower values for maximal inspiratory pressure and vital capacity, the genetic test is helpful in risk stratification $(35,36)$. From the time of DM1 diagnosis, a lifelong cardiac surveillance for arrhythmias and cardiomyopathy, and eventually a prophylactic treatment is a major goal in treating DM1 (37). In any case, cardiac involvement can influence the level of patient autonomy and their performances during everyday life activity. Recently, the importance of periodic cardiologic follow up has been underlined by the clinical
Care Recommendations. This paper stresses the need of more frequent cardiac imaging and ambulatory monitoring to detect asymptomatic arrhythmias, especially in patients aged $>40$ years and with 500-1,000 repeats. Accordingly, a primary prevention pacemaker or ICD in a patient who is at high risk of sudden cardiac death should be considered. Therapy with betaadrenergic blockers, angiotensin-converting enzyme inhibitors, or angiotensin receptor blockers may be considered in patients with reduced ejection fraction (38).

\section{CLINICAL FEATURES OF CNS INVOLVEMENT}

Many literature studies have documented a selective involvement of neuropsychological functioning regarding attention, executive functions, visuo-spatial and visuo-constructive abilities (39). This affects both the cognitive and behavioral personality domains in the patient. In addition to more traditional neuropsychological functioning, in recent years, research has turned its interest into the study of neuropsychiatric comorbidities and pathological behavioral patterns in DM1, identifying the presence of apathy, lack of interest, decrease of emotional interest in activities and irritability (40-42).

The central nervous system alterations described as above are associated with a range of neuropsychological and cognitive dysfunction and can influence important clinical aspects of the disease, like motor function itself, fatigue, depression, sleep alteration and quality of life in its entirety (43). On the other hand, phenotypes associated with CNS involvement can be highly different depending upon the age of disease onset (congenital and childhood form vs. adulthood/late onset forms), this reminiscent, in DM1, of how an altered neurofunctional connectivity can be the mirror of either a neurodevelopmental, or a neurodegenerative disorder.

It is unclear whether CNS dysfunction in DM1 patients is, in its nature, a neurodevelopmental, neurofunctional, and/or neurodegenerative disorder. Longitudinal studies on behavior and cognition in DM1 are few but essential for understating the evolution in time of neuropsychological impairment. A follow up study over 5 years (44) shows a worsening in neuropsychological performances and greater cognitive decline than age matched healthy controls. In the 9-years longitudinal study by Gallais et al. (45), the progression in cognitive scores correlated with age and disease duration, but not with nCTG and the rate of decline, which was higher among the late-onset phenotype than in the adult phenotype (earlier onset and longer duration of the disease were associated with greater cognitive deficits). As already said above, it is worthy to remind that neuropsychological functions can decline in a different way along lifespan, as from the study from Gallais et al. (45) which indicates a more precocious progression rate for language and visual memory executive functions compared to visual attention and speed processing, somehow again supporting that CNS involvement in the adult form likely is due to a neurodegenerative process, still not clear whether or not the cognitive decline reported in DM1 is associated with the development of a tauopathy. The expression 
and the topographic distribution of neurofibrillary tangles in DM1 are similar to what is reported for moderate Alzheimer disease and are higher than that in unaffected individuals of the same age (17).

On the other hand, CNS involvement in congenital and childhood DM1 is due to neurodevelopmental alteration in early life, as longitudinal study showed no further significant decline in cognitive abilities and adaptive behavior over these ages (46).

Brain involvement in congenital DM1 is associated with more severe dysfunctions and is characterized by learning disabilities, intellectual disability, delayed development and psychiatric complaint like phobia, mood disorder and anxiety $(47,48)$. Attention deficit hyperactivity disorder (ADHD) and autism spectrum disorders were also reported in congenital DM1 (49). CNS alterations influence some aspects of motor skills, besides muscle weakness and myotonia. Recently, Naro et al., have showed that gait impairment in patients with DM1 depends also on a muscle network deterioration, secondary to signal synergy deterioration; they suggested that, beyond weakness and myotonia, muscle connectivity deterioration has a pathophysiological role in gait and postural abnormalities, due to peculiar patterns of fronto-parietal and cerebellum-cerebrum disconnection and disorganized projections from premotor to motorcortical network (50).

As an example of how CNS involvement can influence some canonical primary muscular complaints is data indicating that structural and functional brain changes may also influence fatigue in DM1. A previous 3- T MRI ( $\mathrm{T}_{1} / \mathrm{T}_{2} /$ diffusion-weighted) study found a correlation between brain hypoechogenicity of the raphe nucleus with fatigue in DM1 and an inverse correlation between fatigue and the extent of brain white matter hyperintensities $(51,52)$. In neurophysiological studies, both motor cortex excitability, valued by means of transcranial magnetic stimulation measuring intracortical facilitation and inhibition of motor evoked potentials, and central motor conduction time, are also affected in patients with DM1 $(53,54)$.

Increasing evidence from the literature indicate that brain structural and functional abnormalities account with a dominant role for at least some of the specific neuropsychological dysfunctions in DM1 patients. At brain MRI, Diffusion Tensor Imaging (DTI) and Voxel Based Morphometry (VBM) techniques show corticospinal tract involvement, as shown by Park et al. (55) who described a significant correlation between gray matter volume loss in the sensorimotor cortex and white matter micro integrity alteration of corticospinal tract (valued with DTI parameters) and motor parameters such as muscle strength (valued by Medical Research Council scale), 6 min walking test (6MWT) and handgrip, suggesting a role of corticospinal alteration in motor performance in DM1. Also, deep gray matter alterations (caudate, pallidum, hippocampus, subthalamic nucleus, thalamus, and substantia nigra) has been described, with significant relationship with motor function, sleepiness and cognitive functions, particularly attention and executive function (56). CNS involvement also plays a role in sleep disturbance, with prominent REM sleep dysregulation and a narcoleptic-like phenotype in DM1 (57).

\section{Neuroimaging in DM1}

Steinert's disease is the most frequent form of muscular dystrophy in adulthood and it is characterized by a multisystem involvement. Over the years, several neuroimaging studies aimed at assessing the involvement of the CNS in DM1 patients have demonstrated the presence of anomalies affecting both the gray and white matter. The first conventional magnetic resonance imaging (MRI) studies have shown diffuse brain atrophy in DM1 patients compared to healthy controls, and hyperintense lesions affecting the white matter $(39,58,59)$. Subsequent studies have focused on more in-depth analysis through the techniques of Voxel based morphometry (VBM) and diffusion tensor imaging (DTI). The VBM methods have in fact allowed to define a quantitative analysis of the loss of the white and gray matter and to identify the areas in which the loss of gray matter was higher, pointing out a prevalent involvement of the frontal, parietal lobes, middle and upper temporal gyrus and, at the subcortical level, of the basal ganglia and thalamus $(51,59,60)$.

Hyperintensities of the white matter have been described in most of the patients with DM1, and typically are bilateral, asymmetric, and mainly affecting the frontal, temporal and parietal lobes, and some authors have found them in the occipital lobes and anterior temporal poles. An enlargement of the Virchow-Robin spaces was also noted $(51,61,62)$.

Instead, DTI methods analyzing the microstructure of the white substance, showed widespread reduction of fractional anisotropy (FA) and increase in mean diffusivity. Fractional anisotropy reduction involves all four lobes and particularly uncinate fasciculus, forceps, cingulum inferior and superior longitudinal fasciculus. Using tract based spatial statistics, decreased FA affected both association, projection and commissural fibers. Higher Muscular Impairment Rating Scale (MIRS) was associated with lower FA, and patients harboring higher CTG triplets showed a decrease of FA in the fibers, starting in bilateral prefrontal areas, anterior cingulate and temporal cortex insula and putamen $(61,63)$. Ates et al. in 2019 with three Tesla MRI studied iron accumulation in deep gray matter nuclei and they found widespread iron accumulation in caudate, pallidum, hippocampus, subthalamic nucleus, thalamus, and substantia nigra; interestingly these alterations were significantly associated with DM1 common symptoms as muscular weakness, daytime sleepiness, and specific cognitive deficit (56).

Brain CT studies also confirmed generalized brain atrophy, and showed frontal hyperostosis and ventricular dilation (61, 64, 65). Ventricular dilation and macrocephaly has also been described by ultrasound studies in newborns in congenital forms of DM1 (61).

Positron emission tomography (PET) showed global glucose hypometabolism, particularly affecting the frontal and temporal lobes; SPECT study confirmed global cerebral hypoperfusion with frontotemporal predominance $(60,66)$.

Some studies investigated the relationship between genetic parameters and brain alteration, with a positive correlation between longer CTG repeats and greater structural and functional alteration of the brain and muscular impairment 
(67, 68). MRI studies have focused on the correlations between morphological brain abnormalities and cognitive, neuropsychological and social functions, intelligent quotient (IQ) estimate, attention, visuo-constructive and executive performances, and neuropsychological scores which are associated with both global and regional volume decrease, mainly distributed in the frontal, parietal and subcortical regions $(63,69,70)$.

Recently, Gliem et al., in a 5-year longitudinal 3T-brain MRI follow-up study of a group of middle-aged adult-onset DM1 (and DM-2) revealed no significant progression of changes affecting both gray and white matter of the central nervous system over time, hypothesizing a very slow progression or even a stable course of the disease from this point of view in such a patient sample (71).

\section{Cognition Involvement in DM1}

Steinert's disease is characterized by a documented involvement of the central nervous system (CNS) and, also, a neuropsychological functioning impairment so much that over the years, the existence of a "DM1-related-dysexecutivesyndrome" has been proposed $(39,42)$. Several CNS imaging studies, using different imaging techniques, have demonstrated that DM1 patients have brain abnormalities, in particular: (i) a diffuse brain and gray matter (GM) atrophy affecting the frontal, orbitofrontal, temporal and parietal lobes, anterior insular, post cingulate, brainstem nuclei, basal ganglia, hippocampi, parahippocampal, fusiform and lingual areas, thalami, putamen and corpo callosum $(39,51,60,70,72-77)$, (ii) a non-specific alteration of white matter (WM) and ventricular enlargement (51, 66, 78), (iii) an hypometabolism and hypoperfusion of frontal and temporal areas (51, 66); (iv) and microstructural damage of WM in every cerebral lobes and in corticospinal and limbic pathways $(51,79)$; (v), and the enlargement of the hippocampus and amygdala (68).

Although the mechanism underlying CNS involvement in DM1 has not been fully elucidated, some studies suggest that it depends upon a disconnection of the cortical regions, secondary to of the WM tract breakdown $(51,69,74)$. To date it is not yet known whether those CNS involvements in DM1 patients are caused by CNS developmental defects, neurodegenerative processes or both.

\section{Cognitive Domains in Juvanile Form}

The juvenile form of Steinert's Disease is characterized by not ever presence of the classic neurological and motor manifestations, but rather manifesting with the invariant occurrence of cognitive deficits or psychiatric disorders which, in most cases, constitute the onset symptoms of the disease which induce parents to consult the specialist. However, only few systematic studies have investigated this aspect of the disease, despite the crucial role played by cognitive deficits and psychiatric disorders on children's lives.

A review conducted by Douniol et al. in 2009 found that the most common symptoms reported in juvenile forms of DM1 patients was learning disabilities. In particular, in two-thirds of DM1 juvenile patients, learning disabilities correlated with intellectual disability, attention deficit, visual spatial impairment and low cognitive speed. DM1 juvenile patients also showed school difficulties in $69-86.7 \%$ of cases and academy delay (80-83). The study conducted by Gossend (80) showed that from 21 patients who frequented school, $81 \%$ of these were in special education program and only $18 \%$ were in normal school programs. Cohen et al. (81) found that DM1 juvenile patients showed impaired written language skills, although there was no intellectual disability. In particular these patients exhibited reading and spelling impairments, even in presence of a normal word identification. These findings don't seem to correlate with a phonological deficit but with the impaired facial expression and oral motor dysfunction, also with the motor coordination disorder and/or a visual-spatial deficit. Recently Caso et al. (74) found an highest impairment in executive functions in the juvenile forms of DM1 patients respect the adult form, regarding especially phonemic fluency. Another study conducted by Woo et al. (84) found that juvenile DM1 patients, compared to adult DM1 patients, have a significant decline in every component of memory domain including immediate, delayed recall and recognition but not in the executive functioning.

Overall, the profile of the cognitive evaluation of juvenile DM1 patients seem quite consistent with that found in patients with adult form of DM1, as described in the following paragraph.

\section{Cognitive Domains in Adult Form}

Despite DM1 being defined as a muscular disease, is well known that neuropsychological functioning is a crucial feature of this disease (39). Neuropsychological functioning is variable from the subtypes of DM1, indeed congenital forms shows higher impairment compared to adult-onset DM1 patients (48). However, patients with adult-onset DM1 very frequently experience cognitive deficit that can be mostly correlated with frontal pole functioning $(45,85,86)$.

Additionally, several previous studies have found a significantly selective impairment of neuropsychological functioning in DM1 patients respect of healthy controls, in particular regarding executive functioning, attention, visuospatial and visuo-constructive abilities and perceptual reasoning (39, 74, 87-89), with an apparent saving of verbal skills $(39,42,69,90)$. Some studies claim that in DM1 patients with relatively small CTG repeat expansions, cognitive decline may be the only clinical manifestation observed in these patients (85). A study conducted in 66 DM1 patients divided in 22 juveniles and 44 adults showed that there is an impairment in visuo-spatial, visuo-constructive, executive abilities and in naming and visual memory abilities in more than half of DM1 patients (88). Another study showed that DM1 patients have a heterogeneous cognitive profile independent from gender consisting in a significant decline in executive and amnesic domains with a particular visuo-spatial implication and an apparent saving of verbal abilities (69). In particular, this study found that the executive functioning patients showed more deficit in using attention in order to inhibit automatic behavioral responses, by using environmental feedback to shift cognitive sets in using behavior to achieve a goal and in modulating 
the persevering response. These finding seem suggestive of dissociation from verbal to spatial abilities (69). Also, a study conducted by Cabada et al. (91) found the major deficit in visual-constructive, visuo-spatial functions, and alternating attention in $42 \mathrm{DM} 1$ patients compared to 42 healthy controls. A 9 -year longitudinal study that analyzed cognitive functioning in adults with DM1 showed stable verbal fluencies and intelligence quotient and a significant decline over the study period in processing speed in complex executive functioning tasks, verbal memory, and visual attention. Those finding are major in the overall group of adult and late onset DM1 subjects respect to the adult onset group and the percentage of all patients with those cognitive decline increased over the study period (45). A recent review conducted by Okkersen et al. showed that DM1 patients exhibited a significantly worse performance in every neuropsychological domains tested, compared to controls. In particular, it was found that large effect sizes $(0.76-1.01)$ for global cognition, intelligence, visual memory, visuo-spatial perception, visuo-construction, psychomotor speed and social cognition and a small to medium effect sizes (0.33 to 0.66$)$ for language, executive functioning, overall and verbal memory, and attention. It also found that there is a moderate to high statistical heterogeneity in every domain tested except for intelligence, social cognition and global cognition (61). Recently, Fujino et al. evaluated the cognitive functioning of $60 \mathrm{DM} 1$ patients and found that more than half showed several cognitive impairment in particular regarding executive functioning, processing speed, visuo-constructive abilities, attention and working memory (92).

\section{Intelligence}

It is known from previous studies, that DM1 patients have a lower intelligence and an intellectual disability compared to normal control subject in all congenital, childhood and adult onset forms of the disease. The presence of an intellectual disability has been reported by Bird et al. (93) who showed a significantly lower intelligence quotients (IQs), both in adult and congenital onset DM1 patients. Other more recent studies $(48,49)$ found that patients, children and childhood, with mildsevere DM1 congenital form show an intellectual disability. In particular a learning disability was found in $95 \%$ of the severe congenital group, $83 \%$ of the mild congenital group, and $89 \%$ of the childhood DM1 group, globally the severity of DM1 form correlating with a lower IQ total score (49).

Regarding the global, verbal and performance intelligences it was found that intellectual impairment, consisting in low IQ scores both in least severe forms and was also among the classic adult onset forms of DM1 patients, compared to the normative sample mean. In particular this study found that the total mean of global intelligence was 82.6 corresponding to a low IQ average that decreased with disease duration and the increase of the expansion of an unstable trinucleotide cytosine-thymine-guanine (CTG). Mild DM1 patients showed higher scores in global, verbal and performance intelligences than classic adult onset forms. This study also indicated that low IQ scores do not correlate with motor impairment (90).
Recently, Woo et al. (84), in comparing juvenile with adult DM1 patients, found no differences between the two groups in the IQ, while the verbal test was statistically different, juvenile DM1 patients showed lower scores than adult ones, in any case appearing to show a sort of continuum in CNS clinical manifestations along the natural course of this complex multisystemic muscular disorder.

\section{Correlation Between CNS Involvement and Cognitive Deficit}

Although both CNS involvement and impaired neuropsychological functioning have been proven, only a few studies have investigated the correlation between those relationships with discordant results $(51,60,66,74,79)$. The assessment of the functional consequences of the CNS involvement is crucial to evaluate the clinical impact (94).

In order to evaluate the correlation between hypometabolism and functional alteration of prefrontal cortex (PFC) in DM1 patients, Caliandro et al. (95) used a functional near-infrared spectroscopy (fNIRS) during the assessment of a phonemic verbal fluency task ( $\mathrm{pVFT}$ ), and found that DM1 patients showed a lower bilateral activation of the PFC, not associated with cortical atrophy, during the task compared to controls that seems to corroborate the hypometabolism of PFC hypothesis. A study conducted by Baldanzi et al. (42) founded: a correlation between brain parenchymal fraction and visuo-spatial and executive performance; a negative relationship between delayed verbal memory and the grade of atrophy in left postcentral, left middle and inferior temporal gyri and left supramarginal gyrus; a negative relationship between radial diffusivity WM alteration and delayed verbal memory, visuo-spatial memory and spatial organization and visuo-constructional skills; and a significant negative relationship between axial diffusivity and immediate and delayed verbal memory. In addition, a study conducted by Gourdon and Meola (96) showed that the impairment of executive functions, episodic memory and spatial and visuo-constructive abilities was correlated with a widespread atrophy in brain areas. Cabada et al. (91) found a significant correlation between visuo-spatial deficit and a WM major rate lesion, ventricle enlargement and volume loss in the central and anteromedial corpus callosum, bilateral cingulated isthmus, right lateral occipital and right pericalcarine cortex in DM1 patients. A recent review conducted by Minnerop et al. (94) showed that many correlations between brain areas and cognitive functions, especially between flexible thinking and GM volume in the secondary visual cortex; visuo-spatial deficit and volume loss in cingulate isthmus, corpus callosum, right occipital, and pericalcarine cortex and ventricle enlargement, and the delayed recall's component of verbal memory and temporal gyri and supramarginal gyrus. A recent study found an inverse association between perceptual reasoning and processing speed with hippocampal volume in DM1 patients compared to healthy control, that may underlie a specific association from cognitive deficits in adult-onset DM1 and the increased hippocampal volume (77). 


\section{Behavioral Impairment in DM1}

In the last years, pathologic behavioral patterns are frequently reported in DM1 patients, besides cognitive impairments, such as behavioral disorders, apathy, distinctive personality traits, anosognosia, worsening affective and social cognitive symptoms and daytime somnolence (independently by the presence of sleep disordered breathing) (97), and they have been associated to a poorer quality of life $(39,42,60)$, in particular to social and interpersonal difficulties in daily life. Indeed, current studies concerning this topic are consistent and show that these patients have lower social engagement, more psychosocial problems and poorer psychosocial well-being (98-101). Behavior abnormalities were noticed for the first time by Steinert in 1909 and successively several descriptions of suspicious attitude, egocentricity, disagreeableness or indifference $(67,80,102,103)$ or mood disorders (104) were published. Moreover, studies have shown that, as well as for cognitive deficits, behavioral profiles depend on the age of onset. Congenital form is often associated with developmental behavioral disorders, such as autism spectrum disorder, attention deficit and hyperactivity disorder and anxiety disorders $(49,80,105)$. Learning disorders and peer problems are present in infantile and juvenile onset, but they are typically milder than those seen in congenital onset (106). Moreover, with DM1 is also reported alexitimia (48).

While, social cognition deficits are detected in adult onset form, and mainly characterized by dysexecutive behavior, involving harm avoidance (like reluctance to seek new experiences, make new friends or form intimate relationship), a lack of cooperation and empathy, inflexibility and apathy $(40,67)$ and characteristic personality traits (107).

This chapter focuses on adult onset form of DM1, so most of the cited studies have been conducted on these patients. We summarize findings about personality disorders, depression and apathy, social cognition impairment and anosognosia, and their effects on quality of life. Finally, we reflect on importance of psychological well-being in the clinical management of these patients.

\section{Personality Traits}

Clinicians have noticed that DM1 patients have or a tendency to be either obsessive in their health-related care, continuously consulting their referring physician, or contrary avoidant and passive in their attitudes toward health care (39). Currently, a high prevalence of dysfunctional personality has been described and reported in $20-64 \%$ of DM1 patients $(40,41)$. Although previous studies are congruent about the increased frequency of personality disorders in DM1, there are discrepancies on the type of personality traits involved in this disease. In the last 30 years, there were few systematic studies on personality function in DM1 with heterogeneous results. Instead, the most part of research on this topic have been obtained from different data reporting avoidant $(40,67,103)$, dependent $(108,109)$, depressive $(93,108)$, hypochondriac $(93,110)$, obsessive-compulsive (103, 111), passive- aggressive (103), aggressive-sadistic (107), but also paranoid $(103,107,109,110)$, schizotypal (103), and schizoid (93) personality traits.
We analyze the most recent studies between these ones, in Meola et al. (40) report, their results show that although none of the tested patients has fulfilled the criteria for the diagnosis of avoidant personality disorder, DM-1 have displayed significant avoidant behavioral traits compared to control subjects. In general, almost all patients were reluctant to make new friends, carry out new activities, or take personal risks, and the majority of patients were employees with no responsibility or decision-making positions. Results of Winblad et al. (67) are in line with previous data. Authors have indicated the presence of deviant personality in $20 \%$ of DM1 subjects, and in particular higher scores on Harm avoidance and lower on Persistence, Self-directedness and Cooperativeness in comparison with healthy controls (HC) and to patients with other neuromuscular disorders, highlighting tendency to prefer loneliness and not function well in social groups. Different conclusions are reported in the largest study which included 121 patients, it evidences aggressive/sadistic (rash, dogmatic, hostile, competitive, pernicious and explosive behavior) and paranoid traits (thoughts rigidity) (107). Partially different results are reported in Peric et al., work's (109) evaluating 62 patients. They have described the presence of at least one pathological personality trait in $75.8 \%$ of patients, and in $58.1 \%$ after clinical interviews. The most common personality trait was dependent (51.6\%), followed by paranoid $(38.7 \%)$. (110) have partially replicated previous results in 27 patients, whereas $89 \%$ of patients reported elevation on at least 1 clinical scale, and specifically, the most common elevated clinical scores across all patients include paranoia, like previous results, but also schizophrenia and hypochondriasis. Despite its name, schizophrenia scale does not usually indicate the presence of this disorder, but it describes the presence of mental and emotional confusion. Recently, Paunic et al. (111) have published the results of their study, where $44 \mathrm{DM} 1$ patients are a control group compared to 27 genetically confirmed DM2 patients. Their results confirm indirectly, the presence of typical personality traits in DM1 because in DM2 group there was not only a scale with pathological scores, but also, DM2 patients had lower scores compared to DM1 patients in almost all scales.

Concerning the interpretation of personality abnormality there are two hypotheses: the first one is that personality traits could be a direct consequence of DM1 pathology affecting the brain, as shown by atypical connectivity in the default mode network associated with schizotypal-paranoid traits (110) or a severe involvement of the dorsolateral prefrontal cortex, cingulum, medial and lateral parietal regions, occipital and temporal lobes, that has been associated with personality changes in many neurological and psychiatric diseases (74). Second hypothesis is that psychological symptoms arise as a consequence of DM1 clinical manifestations, because factors such as pain and fatigue could also bring patients to avoid social situations and eventually to develop avoidant or schizotypal personality traits in response to the disease.

Above all, there are two strength points: the first is that the prevalence of personality disorders in DM1 is higher than in the general population (that are 6\%) (112). The second is that 
personality traits, and in particular paranoid personality traits have a negative effect on the quality of life (109).

\section{Social Cognition Impairment}

Social cognition deficit seems to be particularly present in childhood onset, given that in this one it has often been detected as autism spectrum disorder (49); while few studies have tried to investigate social cognitive function in adult onset (113115), they often have severe difficulties in daily-living activities including social interaction. Theory of mind (TOM) consist in having a good relationship with others in social context and is probably caused of social interaction deficit in DM1. For this reason, the interest on this topic has increased in the last years and different studies have reported TOM deficit (113, 114, 116, 117). TOM is composed by a cognitive and affective part, with different functional substrates. One study (116) has demonstrated that DM1 patients are more compromised in the affective aspects of TOM than in cognitive parts, because both have the ability to infer the mental states of others by looking at their eyes and the capacity to understand when remarks are inappropriate, are impaired. Both of them have an emotional impact, but on the contrary, patients are able to take other's perspective and understand their interactions or beliefs, which corresponds to the cognitive aspect of TOM. Instead, another study has proved otherwise (117), finding pathological scores in both test assessing TOM in $80 \%$ of sample, and, a more remarkable impairment at TOM story than in Reading the Mind Eyes Test (RMET). Thus, it suggests a weakening of cognitive TOM and characterize the highest executive functions underlying this one (118). Other studies have assessed the integrity of social cognition with facial emotion recognition tasks $(113,114,116,119,120)$ (Kobayakawa et al., 2016). A lot of studies, analyze the ability to recognize each emotion separately and have revealed the same results: DM1 patients scored significantly lower than $\mathrm{HC}$ on the recognition of negative emotion, such as anger, disgust (119) and fear (113). Interestingly, one study has found that the presence of difficulties in processing happiness (120). Moreover, it has been discovered (119) that the facial emotion recognition scores correlate negatively with age, supporting the notion, recently emerged that in DM1 there are age related decline of frontal and temporal functions $(44,45,85,121)$. It is known that facial emotion recognition impairment is a core and early developing feature in fronto-temporal dementia $(122,123)$, so, an important question is still emerging: is emotion recognition a deficit marker of a decline in fronto-temporal functions in DM1 patients? The role of this deficit as a marker of aging related decline is discussed.

Some of these studies $(110,114,115,117,124)$ support the hypothesis that social cognition impairments are a direct consequence of brain abnormalities and not a reaction symptom. Specially because it has been found that subnormal facial and emotional recognition correlates with the size of CTG expansion. So, social, emotion and recognition impairment seems to be a sensitive domain in DM1 (125). For example, in previous studies (115), an association has been found between lesions in the frontal, temporal, and insular sub cortices and decreased emotional sensitivity to disgust and anger among DM1 patients. Another work has highlighted the increase in connectivity in the left fusiform gyrus (FG) that might be associated with impairment in face perception and TOM (110). The same authors, 2 years later (117) discovered an association of TOM scores with specific patterns of abnormal connectivity between the left inferior temporal and fronto-cerebellar nodes in DM1 brains, suggesting that social cognitive impairment in DM1 patients is attributable to impaired emotional processing linked to white matter lesions. In particular, the frontal insula Von Economo neurons seem to be involved in social and emotional behavior (126).

A recent resting-state functional MRI 3T study investigated ventral tegmental area connectivity during subject assessment with the IOWA Gambling task, finding a prominent decisionmaking deficit in patients with DM1. Moreover, this deficit could be related to increased connectivity between brain areas critically involved in the reward/punishment system and social cognition and ventral tegmental area, one of the major sources of diffuse dopaminergic projections in the brain (127).

All these data are relevant not only for a better pathophysiological comprehension of DM1, but also for non-pharmacological interventions to improve clinical aspects and impact on patients' success in life.

\section{Awareness Impairment}

Presence of neuropsychological and behavioral difficulties can bring to reduce awareness of disease burden and progression, and certainly low compliance to treatment. Baldanzi et al. (69), comparing DM1 patient Individualized Neuromuscular Quality of Life Questionnaire (INQoL) self-ratings with the main caregiver's reports, has highlighted that an elevated percentage $(51.6 \%)$ of DM1 subjects was disease unaware. In particular, patients tended to understate some aspects of their psychosocial difficulties, especially Independence (52.4\%) and Social Relationship (47.5\%), suggesting an impairment in self appraisal of their adaptive behaviors and interaction with the environment. The importance of these results is about achievement of an awareness characterization at single domain specificity level. Moreover, lack of awareness results significantly related to the performance failure in cognitive test, in particular cognitive flexibility and visual-spatial memory, in line with some theoretical models that identify self-awareness as a metacognitive function relying on high-order cognitive abilities localized in frontal circuitry and parietal structures $(128,129)$.

\section{Psychological Functioning: Apathy, Depression, and Anxiety}

A recent meta-analysis (130) has estimated pooled prevalence of clinically significant levels of symptoms of depression (19\%), anxiety (17\%), and apathy (55\%) in DM1. Concerning anxiety, different types of anxiety disorder were observed: generalized or separation anxiety disorder and specific phobias (105). Although, some authors have reported that frequency of mood disorders in DM1 is not higher than in general population or in other neuromuscular disease that does not affect the brain directly $(41,131)$, few studies have shown that significant depressiveness in DM1 patients was more common than in $\mathrm{HC}(51,104)$ and in other neuromuscular disorders (132). However, even 
when symptoms of depression and anxiety are registered, only few of DM1 patients meet the criteria for major depression (131) or any psychiatric disorder (40), probably because it is a more pronounced somatic than cognitive-emotional dimension of depression (41). Moreover, it is unclear whether depression is primary or secondary. It has been detected (74) that an association between WM brainstem atrophy at the level of the basal pons and the middle cerebellar peduncles, which can thus be involved in depression and emotional control (133), corroborant the hypothesis that depression in DM1 has at least in part, a pathomorphological correlates and demonstrates that it is not only a reactive phenomenon (74). Another common neuropsychiatric feature detective in DM1 are lack of interesting or also named apathetic behavior $(99,134)$. One study $(99)$ has compared the level of apathy in DM1, Facio-Scapulo-HumeralDystrophy (FSHD) patients and in controls, demonstrating that the global score of apathy was significantly higher in DM1 patients than comparison groups. Indeed, 39.5\% of DM1 patients met the criterion for apathy, contrasting with only $21.1 \%$ of FSHD patients; while, no control subject was apathetic. Results also show that apathy in DM1 is independent of the psychopathological domain, but associated to general cognitive status, suggesting a central cause for apathy in DM1 rather than an adjustment process to cope with the progressive and debilitating nature of the disease. Thus, a better comprehension of apathy and its outcomes in DM1 is relevant, and, in this regard, a clinical routine evaluation is advised.

\section{METHODS TO ASSESS CNS INVOLVEMENT IN DM1 AS POSSIBLE OUTCOME MEASURE}

In clinical practice, as well in research, an outcome measure is a sized mean used to evaluate the effect, both positive or negative, of an intervention or treatment. Outcome measures objectively determine the function of a patient when at the beginning of a clinical trial, and significantly quantify the deviation progress and efficacy of a therapeutic intervention, not only in terms of pure numbers but rather as parameters able to perform the real burden of the disease. Outcomes measures can be then obtained from clinical examinations, laboratory or imaging or functional test or patient-reported.

However, despite the number of studies published in the literature on this topic, there are not comprehensive enough consensus protocols for neuroimaging and cognitive testing in DM1. Recent international workshops stressed the needs to design patient questionnaires and clinical neuropsychological tests to better size and confidently reproduce what cognitive domains of CNS are affected in DM; moreover, more longitudinal natural history studies with CNS measures are strongly needed to understand the pattern of progression and decline in DM1 over time (135). Finally, we also need terms of comparison along longitudinal time-elapsed studies between neuroimaging and neuropsychological data that will help to correlate any decline in cognitive functioning with a change in brain morphology. A consensus for that has been reached on some biomarkers for cerebral involvement in DM1, as from recent workshops that also have risen the needs to create an international DM registry focused on CNS aspects and to collect, for this purpose, blood, muscular tissue, fibroblasts and cerebrospinal fluid in dedicated biobanks $(125,136,137)$. These issues need to be resolved in order to increase readiness for clinical trials in DM.

Following all the above considerations, it comes out that, although with a certain degree of variability within the complex and heterogeneous clinical picture that characterizes DM1, CNS involvement appears nonetheless holding a relevant role in depicting the severity degree of the disease in its entirety as well as its natural course history, reproducing with acceptable assumption illness trajectory. This in turn rises the important question as to whether incorporating clinical or instrumental indices related to CNS involvement into reference outcome measures for treatment interventions can be a valuable tool. Indirect data suggest that this can be the case, as for instance when considering the different scales of health-related quality of life (HRQoL), included those patient-reported, for scores involving most of the considered domains, muscle weakness, pain, fatigue, activities, independence, social relationships, emotions and body image. Nonetheless the general lack of psychometric data still limits the significance of these scales to faithfully figure out the stage of the disease (43).

\section{Indices of Cognitive Impairment}

As it is well known, there are many methods for evaluating the neuropsychological functioning of DM1 patients. A recent review conducted by (78) indicated the instruments most used in the studies present in the literature, listing them according to the frequency with which they had been used.

Assessment of verbal-auditory short and long-term memory: Immediate and Delayed Recall (IR, DR) of Rey Auditory Verbal Learning Test (RAVLT) and Digit Span Test forward and backward.

Assessment of visual-spatial short and long term memory: Copy and Recall (C, R) of Rey Osterrieth Complex Figure (ROCF), and Corsi Block-tapping Test (CBT).

Assessment of selective and shift attention and automatic response inhibition: Trail Making Tests (TMT-A and TMT-B) and Stroop Test.

Assessment of frontal and executive functions: Phonemic verbal fluency test (FAS), Frontal Assessment Battery (FAB) and Wisconsin Card Sorting Test (WCST).

Assessment of visuo-constructive abilities: Rey-Osterrieth Complex Figure copy (ROCF-C); Object assembly and Block Design WAIS subtests.

Assessment of psychomotor speed: Wechsler digit symbol coding (WDS) and Trail making test, part A (TMT-A).

Assessment of intelligence: Raven progressive matrices (RPM) and Wechsler adult intelligence scale (WAIS).

\section{Behavioral Impairment}

Behavioral impairments have been assessed with neuropsychological and psychological instruments. In regards to personality disorders, it is possible to use personality inventory such as Minnesota Multiphasic Personality Inventory (MMPI), 
administered in some studies $(93,110,138)$ or Millon Multiaxal Clinical Inventory (MMCI), also used in other $(107,109,111)$. Both of them are based on Diagnostic Criteria of DSM. Another instrument based on DSM criteria is the Structured Clinical Interview-Personality Disorders (SCID-PD), actually at fifth Version. This instrument has been used in Meola et al. (40) and in (139) studies. In other works $(67,140)$ questionnaires have been used based on biopsychosocial model of personality such as Temperament and Character Inventory (TCI) or inventory based on Big Five model like as questionnaire like NEO five-factor inventory (NEO-FFI).

To assess social cognition, the majority of the studies (116, 117) have used Reading the mind Eyes task (RMT), Faux Pas Test [in (116) and in (119)] also TOM story task [in (117)]. Serra et al. (120) have used a Social Cognition Battery, while in other researches a test has been used to assess Facial Emotion Recognition ability such as the Facial Emotion Recognition Test (POFA), or report questionnaire measure cognitive and affective empathy (TECA) [in (119)].

Individualized Neuromuscular Quality of Life questionnaire (INQoL) (141) has been often used as a measure of QoL [in $(69,88)$ and in $(109)]$. To evaluate the level of depression and anxiety, they have been used principally two questionnaires, like Hamilton scales for depression and anxiety (HamD and HamA) [in (88)] and Beck Depression Inventory (BDI) [in (41) and in (74)]. Finally, to measure the presence of apathy the Apathy Evaluation Scale [in (99)] has been used to asses incidence of anosoagnosia (69), and a comparison has been done to evaluate the statistical agreement either between the severity of motor impairment scored by MIRS (administered by a trained clinician) and symptoms complained by patients and assessed by INQoL Weakness Domain (administered by a psychologist) or between Insole separately administered to both patient and to the main caregiver.

As technology is becoming an increasingly more important part in the medical field, new tools and instruments are available for health professionals to assess in a more real life complex behavioral-cognitive profiles. One of these new technologies is represented by serious games, games developed with a primary purpose other than entertainment and are currently being used in several fields, from education, social and environmental contexts, to health care areas. Firstly applied in mild cognitive impairment, but also in normal aging, they have recently found space in the purpose of assessment, follow up and rehabilitation for different pathologies, in addition to conventional treatment and rehabilitation (142). Many other potential applications are currently being studied for these tools, for instance, to assess executive functions (143), a reason why new technology appears potentially suitable for DM1, eventually in addition with physical stimulation, indicating (unpublished data) a promising usefulness as quantifiable and comfortable method of clinical evaluation in a domestic environment.

\section{Neuroimaging Outcome Measures}

An international consensus on neuroimaging outcome measures in DM1 does not exist, however, the published case studies and literature reviews have described numerous resonance parameters to be evaluated, the evolution of which over time is however uncertain. The most frequently applied techniques are morphological MRIs, evaluating brain atrophy and white matter affection, with a few studies using functional MRI (136). Additional longitudinal neuroimaging studies will permit determining the natural history of the CNS affection and to help to differentiate between developmental defects, neurodegeneration, and age-related lesions (136). A standardization of software and of MRI analysis method is strongly needed.

According to the 2014 workshop report of the DM-CNS group, among the most used MRI techniques, the quantification of brain volume by voxel-based morphometry (VBM) automated segmentation procedure of T1-weighted MR images has a dominant role and allows an objective calculation of gray and white matter volumes and abnormalities (125).

Regarding quantification of global and regional brain volume, numerous parameters are described such as the brainparenchima factor (BPF, the ratio of brain parenchymal volume to intracranial volume, Kassubek), callosal volume (144), the gray matter to white matter ratio (145). As regard to quantification of white matter abnormalities, the most widely used techniques are signal changes evaluation on T2-weighted images (62), diffusion tensor imaging (DTI) study parameters (fractional anisotropy, mean diffusivity, radial and axial diffusivity) (79). Other possible imaging outcome measures are proton MR spectroscopy evaluating single-voxel brain metabolities $[\mathrm{N}$ acetylaspartate, phosphocreatine, choline and lactate, (146)], glucose consumption on 18FDG PET, cerebral blood flow on SPECT (40), Table 1 summarizes clinical instruments in the considered domains to assess CNS involvement in DM1.

\section{CNS Outcome Measures: Why a Myologist Can Still Remain a Neurologist in Caring of CNS Involvement for Clinical Trials in DM-1}

In 2011 and subsequently in 2013, the first workshops on outcome measures in patients with type 1 myotonic dystrophy were carried out with the aim of outlining outcome measures that can be used in the therapeutic trails of these patients $(147,148)$. After that, increasing interest has been focused on the attempt to get informative and reliable items able to depict at the best disease trajectory in DM1 (7). Related questions to be dealt with to this regards include, like many other chronic progressive illnesses and in the lack of decisive therapies, the high phenotypic heterogeneity of the disease, existence of far different clinical forms and the very slow progression rate of it from one side; the reliability of the outcome measure in terms of inter- and intraobserved variability, its fidelity to reproduce clinically relevant complain and its capacity, in front of a minimum deviation over time, to be caught with the maximal significance by a given therapy efficacy in a given patient sample size, from the other side. While already difficult for myopathic core features of DM1, the answers to these questions appear even more arduous when dealing with CNS involvement manifestations due to the complexity of their clinical interpretation and evaluation. In their recent study, Gliem et al. (71) found minimal if any modifications 
TABLE 1 | Central Nervous System involvement in DM1: tools for cognitive and behavioral measures and for Neurological/neuroimaging assessment.

\begin{tabular}{ll}
\hline Cognitive section & \\
\hline $\begin{array}{l}\text { Verbal-auditory short and } \\
\text { long-term memory }\end{array}$ & $\begin{array}{l}\text { Immediate and Delayed Recall (IR, DR) of Rey } \\
\text { Auditory Verbal Learning Test (RAVLT) and Digit } \\
\text { Span Test forward and backward }\end{array}$ \\
$\begin{array}{l}\text { Visual-spatial short and } \\
\text { long-term memory }\end{array}$ & Copy and Recall (C, R) of Rey Osterrieth \\
& Complex Figure (ROCF), and Corsi \\
Selective and shift attention & Block-tapping Test (CBT) \\
and automatic response & Trail Making Tests (TMT-A and TMT-B) and \\
inhibition & Stroop Test \\
Frontal and executive & \\
functions & Phonemic verbal fluency test (FAS); Frontal \\
& Assessment Battery (FAB) and Wisconsin Card \\
Assessment of & Sorting Test (WCST) \\
visuo-constructive abilities & Rey-Osterrieth Complex Figure copy \\
& (ROCF-C); Object assembly and Block Design \\
Psychomotor speed & WAIS subtests \\
& Rey-Osterrieth Complex Figure copy \\
(ROCF-C); Object assembly and Block Design \\
WAIS subtests \\
Raven progressive matrices (RPM) and \\
Wechsler adult intelligence scale (WAIS) \\
\end{tabular}

Behavioral section

\begin{tabular}{ll}
\hline Domain & Tools \\
\hline Personality & Minnesota Multiphasic Personality Inventory \\
& (MMPI) Millon Multiaxal Clinical Inventory \\
& (MMCI) Structured Clinical Interview-Personality \\
& Disorders (SCID) Temperament and Character \\
& Inventory (TCI) Big Five model like as \\
& questionnaire like NEO five-factor inventory \\
& Reading the mind Eyes task (RME) Faux Pas \\
& Test TOM story task Social Cognition Battery \\
& Facial Emotion Recognition Test Report \\
& questionnaire measure cognitive and affective \\
Social Cognition & Individualized Neuromuscular Quality of Life \\
& questionnaire (INQoL) Health-related quality of \\
life (HRQL), & Hamilton scales for depression and anxiety \\
(HamD and HamA) Beck Depression & Inventory (BDI) \\
Anosoagnosia & Apathy Evaluation Scale \\
impairment and patient/caregiver comparison \\
of subjective clinical symptoms \\
Depression and Anxiety
\end{tabular}

Neurological section

Brain morphology

Multidimensional selfreported scale

Magnetic Resonance imaging (MRi) Voxel Based Morphometry (VBM) Diffusion Tensor Imaging (DTI) Magnetic Resonance spectroscopy (MRS)

DM1-ActiveC Myotonic Dystrophy Health Index that, although frequently informative compared to normal in cross-sectional studies, alterations in CNS parameters can lose clinical significance over time.

As above stated, the main outcome measures actually used to study central nervous system and cognitive impairment in DM1 patients are represented by neuropsychological tests, in particular for frontal functions, attention, executive performance and language, Frontal Systems Behavior Scale, Cambridge Brain Sciences computerized (online) testing, as well as neuroimaging MRI with Voxel based Morphometry and Diffusion Tensor Imaging sequences. A recent study has also shown how the outcome measures currently used for cognitive and central nervous system involvement can be influenced by the peripheral component of the disease, highlighting the need to carry out longitudinal and large case studies to evaluate the best outcome measures to be adopted in DM1 (89).

In addition to these objective outcome measures, a group of self-reported outcome measure are described. Some have been specifically developed for use in DM1 patients, including DM1ActivC, a measure of capacity for activity and social participation, and the fatigue and daytime sleepiness scale (FDSS) $(149,150)$. DM1-ActivC, in a recent trial, has been shown to significantly improve after a 10-months trial of cognitive behavioral therapy, which ameliorated ability to complete activities of daily living and social participation (151). The Myotonic Dystrophy Health Index (MDHI) is self-reported rate of symptoms in a multidomains scale which includes social performance, fatigue and also cognitive complaints (152).

All the above considerations, also taking into account of the clinical relevance of CNS damage manifestations in DM1, underline the necessity to further develop this area of study in the attempt to improve the level of reliability of available biomarkers in this regard. At the same time, this arises a provocative and even paradoxical question on how the myologist, by now the figure in charge to care of a patient with DM1, needs to remain a neurologist to keep his skills so high to better appreciate this important aspect of Steinert disease.

\section{CONCLUSIONS}

Preliminary data are present in a recent trial by Okkersen et al. (151). Results show that cognitive-behavioral therapy increased DM1-Active-c score at 10 months, that is a measure of activity capacity and social participation. Moreover, interestingly secondary outcome measures, like total distance on the 6min walking test, daily activity levels and objective physical activity are significantly improved, whereas fatigue and daytime sleepiness scale score are decreased. Both beneficial effects on primary and secondary outcomes were sustained at 16 months. On the contrary, depression and apathy evaluations were stable (135). So, currently data, although at the moment there is a lack of strength empirical studies on this regard, encourage to provide DM1 patients and their families with neurocognitive rehabilitation as well as psychological support programs (86).

The first one should be focused on attention, memory and executive function, including goal management training of both neuropsychological and 3T brain MRI parameters of a period of 5 years follow up in 16 mean-aged adult form DM1, as well as in an equal number of DM2, patients, indicating 
approach, already successfully applied in people with neurological conditions, and problem-solving training, metacognitive or self-instructional training that encouraging patients to plan and reduce impulsivity (153). The second one should be focused on disease awareness and coping strategies. It has been demonstrated that dysexecutive syndrome and behavioral problems significantly impact on QoL and it has been suggested that cognitive rehabilitation may improve patients' QoL (88), In particular in adult onset group where QoL is more impaired (109), likely because late onset of the disease causes greater frustration, while an adjustment to the disabling disease since childhood in DM1 juvenile onset.

In conclusion, summarizing all the available literature, data emphasize the importance to evaluate CNS symptoms, including neuroimaging data and cognitive and behavioral measures, in routine clinical management of DM1 patients by searching for suitable outcome measures for that. Tools developed from observational prolonged trials and ultimately targeted to mirror patient's quality of life will be of great importance for considering that (154). Brain dysfunctions could play a crucial role in emerging of most of the clinical features characterizing this neuromuscular disease. Through animal model it was possible identified molecular outputs that could play a prominent role as CFS biomarkers for human DM1 patients (96). In line with this, the majority of existing studies highlights the implication of CNS involvement also in planning rehabilitation strategies targeted to improve aspects that have an impact on quality of life beyond medical management of these patients. The safe of QoL parallel to medical measures, means improving also support of caregiver system and efficiency of the entire assistive system. In doing

\section{REFERENCES}

1. Emery AE. Population frequencies of inherited neuromuscular diseases-a world survey. Neuromusc Disord. (1991) 1:1929. doi: 10.1016/0960-8966(91)90039-U

2. Udd B, Krahe R. The myotonic dystrophies: molecular, clinical, and therapeutic challenges. Lancet Neurol. (2012) 11:891-905. doi: 10.1016/S1474-4422(12)70204-1

3. Brook JD, McCurrach ME, Harley HG, Buckler AJ, Church D, Aburatani H, et al. Molecular basis of myotonic dystrophy: expansion of a trinucleotide (CTG) repeat at the 3 end of a transcript encoding a protein kinase family member. Cell. (1992) 68:799-808. doi: 10.1016/0092-8674(92)9 0154-5

4. Huang C, Kuo H. Myotonic dystrophies. Chang Gung Med J. (2005) 28:517. doi: 10.12871/000398292017125

5. Larkin K, Fardaei M. Myotonic dystrophy-a multigene disorder. Brain Res Bull. (2001) 56:389-95. doi: 10.1016/S0361-9230(01)00656-6

6. Llagostera E, Catalucci D, Marti L, Liesa M, Camps M, Ciaraldi $\mathrm{TP}$, et al. Role of myotonic dystrophy protein kinase (DMPK) in glucose homeostasis and muscle insulin action. PLoS ONE. (2007) 2:e1134. doi: 10.1371/journal.pone.0001134

7. Cumming SA, Jimenez-Moreno C, Okkersen K, Wenninger S, Daidj F, Hogarth F, et al. Genetic determinants of disease severity in the myotonic dystrophy type 1 OPTIMISTIC cohort. Neurology. (2019) 93:e9951009. doi: 10.1212/WNL.0000000000008056

8. Li M, Zhuang Y, Batra R, Thomas JD, Li M, Nutter CA, et al. HNRNPA1induced spliceopathy in a transgenic mouse model of myotonic dystrophy. Proc Natl Acad Sci USA. (2020) 117:5472-7. doi: 10.1073/pnas.1907297117

9. Wang PY, Lin YM, Wang LH, Kuo TY, Cheng SJ, Wang GS. Reduced cytoplasmic MBNL1 is an early event in a brain-specific mouse that, additional knowledge will also come from collaboration initiatives and consortia between different expert centers across the world, as it has been the case of the outcome measures in myotonic dystrophy (OMMYD) group that has been working to reach consensus statements in some key areas over the last few years (148). Although much else still remains to be done, also from this point of view the main objective remains to build upon fundamental synergistic initiatives, for instance, data sharing and global registries, instruments to better define strategies for accelerating trial readiness in DM1.

\section{AUTHOR CONTRIBUTIONS}

CS, GSp, EL, and GSi: examining scientific literature, participation to experimental approach, and writing the paper. GSi: also supervising conclusive form. LS: contribution to experimental approach. CA and GR: contribution to experimental approach and advise. All authors contributed to the article and approved the submitted version.

\section{FUNDING}

The authors are grateful to the following supporting and funding subjects: European Reference Network for Neuromuscular Diseases (ERN EURO-NMD), UILDM (Unione Italiana Lotta alla Distrofia Muscolare), and AFM-Telethon (Grant Number 17191) for the Patient Associations side, Rotary Foundation (Global Grant Number 1862130) as Charity, Aliveda and former DMF now Difass-Foodar as Drug Companies interested in this work. model of myotonic dystrophy. Human Mol Genet. (2017) 26:224757. doi: $10.1093 / \mathrm{hmg} / \mathrm{ddx} 115$

10. Lee JE, Cooper TA. Pathogenic mechanisms of myotonic dystrophy. (2009) 37:1281-6. doi: 10.1042/BST0371281

11. Fernandez-Gomez F, Tran H, Dhaenens CM, Caillet-Boudin ML, SchraenMaschke S, Blum D, et al. Myotonic dystrophy: an RNA toxic gain of function tauopathy? In: Tau Biology. Singapore: Springer (2019). p. 207-16.

12. Swinnen B, Robberecht W, Van Den Bosch L. RNA toxicity in non-coding repeat expansion disorders. EMBO J. (2020) 39:1-23. doi: 10.15252/embj.2018101112

13. Orengo JP, Chambon P, Metzger D, Mosier DR, Snipes GJ, Cooper TA. Expanded CTG repeats within the DMPK $3{ }^{\prime}$ UTR causes severe skeletal muscle wasting in an inducible mouse model for myotonic dystrophy. Proc Natl Acad Sci USA. (2008) 105:2646-51. doi: 10.1073/pnas.0708519105

14. Perfetti A, Greco S, Cardani R, Fossati B, Cuomo G, Valaperta R, et al. Validation of plasma microRNAs as biomarkers for myotonic dystrophy type 1. Sci Rep. (2016) 6:38174. doi: 10.1038/srep38174

15. Baldanzi S, Ricci G, Bottari M, Chico L, Simoncini C, Siciliano G. The proposal of a clinical protocol to assess central and peripheral fatigue in myotonic dystrophy type 1. Arch Ital Biol. (2017) 155:43-53. doi: $10.12871 / 000398292017125$

16. Siciliano G, Pasquali L, Rocchi A, Falorni M, Galluzzi F, Rocco A, et al. Advanced oxidation protein products in serum of patients with myotonic disease type I: association with serum gammaglutamyltransferase and disease severity. Clin Chem Lab Med. (2005) 43:745-7. doi: 10.1515/CCLM.2005.127

17. Caillet-Boudin ML, Fernandez-Gomez FJ, Tran-Ladam H, Buee L, Sergeant N. Brain pathology in myotonic dystrophy: when tauopathy meets spliceopathy and RNAopathy. Front Mol Neurosci. (2014) 6:57. doi: 10.3389/fnmol.2013.00057 
18. Hernández-Hernández O, Guiraud-Dogan C, Sicot G, Huguet A, Luilier S, Steidl E, et al. Myotonic dystrophy CTG expansion affects synaptic vesicle proteins, neurotransmission and mouse behaviour. Brain. (2013) 136:95770. doi: 10.1093/brain/aws367

19. Dhaenens CM, Tran H, Frandemiche ML, Carpentier C, Schraen-Maschke $\mathrm{S}$, Sistiaga A, et al. Mis-splicing of Tau exon 10 in myotonic dystrophy type 1 is reproduced by overexpression of CELF2 but not by MBNL1 silencing. Biochim Biophy Acta. (2011) 1812:732-42. doi: 10.1016/j.bbadis.2011.03.010

20. De Antonio M, Dogan C, Hamroun D, Mati M, Zerrouki S, Eymard B, et al. Unravelling the myotonic dystrophy type 1 clinical spectrum: a systematic registry-based study with implications for disease classification. Rev Neurol. (2016) 172:572-80. doi: 10.1016/j.neurol.2016.08.003

21. Wenninger S, Montagnese F, Schoser B. Core clinical phenotypes in myotonic dystrophies. Front Neurol. (2018) 9:303. doi: 10.3389/fneur.2018.00303

22. Mathieu J, Boivin H, Meunier D, Gaudreault M, Begin P. Assessment of a disease-specific muscular impairment rating scale in myotonic dystrophy. Neurology. (2001) 56:336-40. doi: 10.1212/WNL.56.3.336

23. Peric S, Bjelica B, Bozovic I, Pesovic J, Paunic T, Banovic M, et al. Fatigue in myotonic dystrophy type 1: a seven-year prospective study. Acta Myol. (2019) 38:239.

24. Heskamp L, van Nimwegen M, Ploegmakers MJ, Bassez G, Deux JF, Cumming SA, et al. Lower extremity muscle pathology in myotonic dystrophy type 1 assessed by quantitative MRI. Neurology. (2019) 92:e280314. doi: 10.1212/WNL.0000000000007648

25. Solbakken G, Bjørnarå B, Kirkhus E, Nguyen B, Hansen G, Frich JC, et al. MRI of trunk muscles and motor and respiratory function in patients with myotonic dystrophy type 1. BMC Neurol. (2019) 19:135. doi: 10.1186/s12883-019-1357-8

26. Hawkins AM, Hawkins CL, Razak KA, Khoo TK, Tran K, Jackson RV. Respiratory dysfunction in myotonic dystrophy type 1: a systematic review. Neuromus Disord. (2019) 29:198-212. doi: 10.1016/j.nmd.2018.12.002

27. Monteiro R, Bento J, Gonçalves MR, Pinto T, Winck JC. Genetics correlates with lung function and nocturnal ventilation in myotonic dystrophy. Sleep Breath. (2013) 17:1087-92. doi: 10.1007/s11325-013-0807-6

28. Henke C, Spiesshoefer J, Kabitz HJ, Herkenrath S, Randerath W, Brix T, et al. Characteristics of respiratory muscle involvement in myotonic dystrophy type 1. Neuromusc Disord. (2020) 30:17-27. doi: 10.1016/j.nmd.2019.10.011

29. Rossi S, Della Marca G, Ricci M, Perna A, Nicoletti TF, Brunetti V, et al. Prevalence and predictor factors of respiratory impairment in a large cohort of patients with Myotonic Dystrophy type 1 (DM1): A retrospective, cross sectional study. J Neurol Sci. (2019) 399:11824. doi: 10.1016/j.jns.2019.02.012

30. Poussel M, Thil C, Kaminsky P, Mercy M, Gomez E, Chaouat A, et al. Lack of correlation between the ventilatory response to $\mathrm{CO}_{2}$ and lung function impairment in myotonic dystrophy patients: evidence for a dysregulation at central level. Neuromusc Disord. (2015) 25:4038. doi: 10.1016/j.nmd.2015.02.006

31. Sansone VA, Gagnon C. 207th ENMC Workshop on chronic respiratory insufficiency in myotonic dystrophies: management and implications for research, 27-29 June 2014, Naarden, The Netherlands. Neuromusc Disord. (2015) 25:432-42. doi: 10.1016/j.nmd.2015.01.011

32. Wahbi K, Furling D. Cardiovascular manifestations of myotonic dystrophy. Trends CardiovascMed. (2019) 30:232-8. doi: 10.1016/j.tcm.2019.06.001

33. Groh WJ, Groh MR, Saha C, Kincaid JC, Simmons Z, Ciafaloni E, et al. Electrocardiographic abnormalities and sudden death in myotonic dystrophy type 1. New Engl J Med. (2008) 358:2688-97. doi: 10.1056/NEJMoa062800

34. Laurent V, Pellieux S, Corcia P, Magro P, Pierre B, Fauchier L, et al. Mortality in myotonic dystrophy patients in the area of prophylactic pacing devices. Int J Cardiol. (2011) 150:54-8. doi: 10.1016/j.ijcard.2010.02.029

35. McNally EM, Sparano D. Mechanisms and management of the heart in myotonic dystrophy. Heart. (2011) 97:1094100. doi: 10.1136/hrt.2010.214197

36. Boussaïd G, Wahbi K, Laforet P, Eymard B, Stojkovic T, Behin $\mathrm{A}$, et al. Genotype and other determinants of respiratory function in myotonic dystrophy type 1. NeuromuscDisord. (2018) 28:222-8. doi: 10.1016/j.nmd.2017.12.011
37. Ashizawa T, Gagnon C, Groh WJ, Gutmann L, Johnson NE, Meola $\mathrm{G}$, et al. Consensus-based care recommendations for adults with myotonic dystrophy type 1. Neurol Clin Pract. (2018) 8:507-20. doi: 10.1212/CPJ.0000000000000531

38. McNally EM, Mann DL, Pinto Y, Bhakta D, Tomaselli G, Nazarian $\mathrm{S}$, et al. Clinical care recommendations for cardiologists treating adults with myotonic dystrophy. J Am Heart Assoc. (2020) 9:e014006. doi: 10.1161/JAHA.119.014006

39. Meola G, Sansone V. Cerebral involvement in myotonic dystrophies. Muscle Nerve. (2007) 36:294-306. doi: 10.1002/mus.20800

40. Meola G, Sansone V, Perani D, Scarone S, Cappa S, Dragoni C, et al. Executive dysfunction and avoidant personality trait in myotonic dystrophy type 1 (DM-1) and in proximal myotonic myopathy (PROMM/DM-2). Neuromusc Disord. (2003) 13:813-21. doi: 10.1016/S0960-8966(03)00137-8

41. Winblad S, Jensen C, Månsson JE, Samuelsson L, Lindberg C. Depression in myotonic dystrophy type 1: clinical and neuronal correlates. Behav Brain Funct. (2010) 6:25. doi: 10.1186/1744-9081-6-25

42. Baldanzi S, Bevilacqua F, Lorio R, Volpi L, Simoncini C, Petrucci $A$, et al. Disease awareness in myotonic dystrophy type 1: an observational cross-sectional study. Orphanet J Rare Dis. (2016) 11:34. doi: 10.1186/s13023-016-0417-Z

43. Landfeldt E, Nikolenko N, Jimenez-Moreno C, Cumming S, Monckton DG, Gorman G, et al. Disease burden of myotonic dystrophy type 1. J Neurol. (2019) 266:998-1006. doi: 10.1007/s00415-019-09228-w

44. Winblad S, Samuelsson L, Lindberg C, Meola G. Cognition in myotonic dystrophy type 1: a 5-year follow-up study. Eur J Neurol. (2016) 23:14716. doi: $10.1111 /$ ene. 13062

45. Gallais B, Gagnon C, Mathieu J, Richer L. Cognitive decline over time in adults with myotonic dystrophy type 1: a 9-year longitudinal study. Neuromusc Disord. (2017) 27:61-72. doi: 10.1016/j.nmd.2016.10.003

46. Lindeblad G, Kroksmark AK, Ekström AB. Cognitive and adaptive functioning in congenital and childhood forms of myotonic dystrophy type 1: a longitudinal study. Dev Med Child Neurol. (2019) 61:121420. doi: 10.1111/dmcn.14161

47. Angeard N, Jacquette A, Gargiulo M, Radvanyi H, Moutier S, Eymard B, et al. A new window on neurocognitive dysfunction in the childhood form of myotonic dystrophy type 1 (DM1). Neuromusc Disord. (2011) 21:46876. doi: 10.1016/j.nmd.2011.04.009

48. Douniol M, Jacquette A, Cohen D, Bodeau N, Rachidi L, Angeard $\mathrm{N}$, et al. Psychiatric and cognitive phe- notype of childhood myotonic dystrophy type 1. Dev Med Child Neurol. (2012) 54:905-11. doi: 10.1111/j.1469-8749.2012.04379.x

49. Ekström AB, Hakenäs-Plate L, Samuelsson L, Tulinius M, Wentz E. Autism spectrum conditons in myotonic dystrophy type 1: a study on 57 individuals with congenital and childhood forms. Am J Med Genet Part B Neuropsychiatr Genet. (2008) 147:918-26. doi: 10.1002/ajmg.b.30698

50. Naro A, Portaro S, Milardi D, Billeri L, Leo A, Militi D, et al. Paving the way for a better understanding of the pathophysiology of gait impairment in myotonic dystrophy: a pilot study focusing on muscle networks. J Neuroeng Rehabil. (2019) 16:1-14. doi: 10.1186/s12984-019-0590-0

51. Minnerop M, Weber B, Schoene-Bake JC, Roeske S, Mirbach S, Anspach C, et al. The brain in myotonic dystrophy 1 and 2: evidence for a predominant white matter disease. Brain. (2011) 134:3530-46. doi: 10.1093/brain/awr299

52. Peric S, Pavlovic A, Ralic V, Dobricic V, Basta I, Lavrnic D, et al. Transcranial sonography in patients with myotonic dystrophy type 1. Muscle Nerve. (2014) 50:278-82. doi: 10.1002/mus.24162

53. Boërio D, Lefaucheur JP, Bassez G, Hogrel JY. Central and peripheral components of exercise-related fatigability in myotonic dystrophy type 1 . Acta Neurol Scand. (2012) 125:38-46. doi: 10.1111/j.1600-0404.2011.01497.x

54. Portaro S, Naro A, Chillura A, Billeri L, Bramanti A, Bramanti P, et al. Toward a more personalized motor function rehabilitation in Myotonic dystrophy type 1: The role of neuroplasticity. PloS ONE. (2017) 12:e0178470. doi: 10.1371/journal.pone. 0178470

55. Park JS, Song H, Jang KE, Cha H, Lee SH, Hwang SK, et al. Diffusion tensor imaging and voxel-based morphometry reveal corticospinal tract involvement in the motor dysfunction of adult-onset myotonic dystrophy type 1. Sci Rep. (2018) 8:1-11. doi: 10.1038/s41598-018-34048-9 
56. Ates S, Deistung A, Schneider R, Prehn C, Lukas C, Reichenbach JR, et al. Characterization of iron accumulation in deep grey matter in Myotonic Dystrophy type 1 and 2 using quantitative susceptibility mapping and R2* relaxometry: a magnetic resonance imaging study at 3 Tesla. Front Neurol. (2019) 10:1320. doi: 10.3389/fneur.2019.01320

57. Bonanni E, Carnicelli L, Crapanzano D, Maestri M, Simoncini C, Baldanzi $\mathrm{S}$, et al. Disruption of sleep-wake continuum in myotonic dystrophy type 1: beyond conventional sleep staging. Neuromusc Disord. (2018) 28:41421. doi: 10.1016/j.nmd.2018.02.004

58. Chang L, Anderson T, Migneco OA, Boone K, Mehringer CM, VillanuevaMeyer J, et al. Cerebral abnormalities in myotonic dystrophy: cerebral blood flow, magnetic resonance imaging, and neuropsychological tests. Arch Neurol. (1993) 50:917-23. doi: 10.1001/archneur.1993.00540090024006

59. Kassubek J, Juengling FD, Hoffmann S, Rosenbohm A, Kurt A, Jurkat-Rott K, et al. Quantification of brain atrophy in patients with myotonic dystrophy and proximal myotonic myopathy: a controlled 3-dimensional magnetic resonance imaging study. Neurosci Lett. (2003) 348:73-6. doi: 10.1016/S0304-3940(03)00740-7

60. Weber YG, Roebling R, Kassubek J, Hoffmann S, Rosenbohm A, Wolf $\mathrm{M}$, et al. Comparative analysis of brain structure, metabolism, and cognition in myotonic dystrophy 1 and 2. Neurology. (2010) 74:110817. doi: 10.1212/WNL.0b013e3181d8c35f

61. Okkersen K, Monckton DG, Le N, Tuladhar AM, Raaphorst J, van Engelen BG. Brain imaging in myotonic dystrophy type 1: a systematic review. Neurology. (2017) 89:960-9. doi: 10.1212/WNL.0000000000004300

62. Di Costanzo A, Di Salle F, Santoro L, Bonavita V, Tedeschi G. Dilated Virchow-Robin spaces in myotonic dystrophy: frequency, extent and significance. Eur Neurol. (2001) 46:131-9. doi: 10.1159/000050786

63. Labayru G, Diez I, Sepulcre J, Fernández E, Zulaica M, Cortés JM, et al. Regional brain atrophy in gray and white matter is associated with cognitive impairment in Myotonic Dystrophy type 1. NeuroImage Clin. (2019) 24:102078. doi: 10.1016/j.nicl.2019.102078

64. Sinforiani E, Sandrini G, Martelli A, Mauri M, Uggetti C, Bono G, et al. Cognitive and neuroradiological findings in myotonic dystrophy. Funct Neurol. (1991) 6:377-84.

65. Avrahami E, Katz A, Bornstein N, Korczyn AD. Computed tomographic findings of brain and skull in myotonic dystrophy. J Neurol Neurosurg Psychiatry. (1987) 50:435-8. doi: 10.1136/jnnp.50.4.435

66. Romeo V, Pegoraro E, Squarzanti F, Sorarù G, Ferrati C, Ermani M, et al. Retrospective study on PET-SPECT imaging in a large cohort of myotonic dystrophy type 1 patients. Neurol Sci. (2010) 31:75763. doi: 10.1007/s10072-010-0406-2

67. Winblad S, Lindberg C, Hansen S. Temperament and character in patients with classical myotonic dystrophy type 1 (DM-1). Neuromusc Disord. (2005) 15:287-92. doi: 10.1016/j.nmd.2004.12.003

68. van der Plas E, Hamilton MJ, Miller JN, Koscik TR, Long JD, Cumming S, et al. Brain structural features of myotonic dystrophy type 1 and their relationship with CTG repeats. I Neuromusc Dis. 6:32132. doi: 10.3233/JND-190397

69. Baldanzi S, Cecchi P, Fabbri S, Pesaresi I, Simoncini C, Angelini C, et al. Relationship between neuropsychological impairment and grey and white matter changes in adult-onset myotonic dystrophy type 1. NeuroImage Clin. (2016) 12:190-7. doi: 10.1016/j.nicl.2016.06.011

70. Romeo V, Pegoraro E, Ferrati C, Squarzanti F, Soraru G, Palmieri A, et al. Brain involvement in myotonic dystrophies: neuroimaging and neuropsychological comparative study in DM1 and DM2. J Neurol. (2010) 257:1246-55. doi: 10.1007/s00415-010-5498-3

71. Gliem C, Minnerop M, Roeske S, Gärtner H, Schoene-Bake JC, Adler S, et al. Tracking the brain in myotonic dystrophies: A 5-year longitudinal follow-up study. PLoS ONE. (2019) 14:e0213381. doi: 10.1371/journal.pone.0213381

72. Sergeant N, Sablonnière B, Schraen-Maschke S, Ghestem A, Maurage CA, Wattez A, et al. Dysregulation of human brain microtubule-associated tau mRNA maturation in myotonic dystrophy type 1. Human Mol Genet. (2001) 10:2143-55. doi: 10.1093/hmg/10.19.2143

73. Itoh K, Mitani M, Kawamoto K, Futamura N, Funakawa I, Jinnai K, et al. Neuropathology does not correlate with regional differences in the extent of expansion of CTG repeats in the brain with myotonic dystrophy type 1. Acta Histochem Cytochem. (2010) 1012160093. doi: 10.1267/ahc.10019
74. Caso F, Agosta F, Peric S, Rakoèeviæ-Stojanoviæ V, Copetti M, Kostic VS, et al. Cognitive impairment in myotonic dystrophy type 1 is associated with white matter damage. PLoS ONE. (2014) 9:e104697. doi: 10.1371/journal.pone.0104697

75. Schneider-Gold C, Bellenberg B, Prehn C, Krogias C, Schneider R, Klein J, et al. Cortical and subcortical grey and white matter atrophy in myotonic dystrophies type 1 and 2 is associated with cognitive impairment, depression and daytime sleepiness. PLoS ONE. (2015) 10:e0130352. doi: 10.1371/journal.pone.0130352

76. Sugiyama A, Sone D, Sato N, Kimura Y, Ota M, Maikusa N, et al. Brain gray matter structural network in myotonic dystrophy type 1. PLoS ONE. (2017) 12:e0187343. doi: 10.1371/journal.pone.0187343

77. Langbehn KE, van der Plas E, Moser DJ, Long JD, Gutmann L, Nopoulos PC. Cognitive function and its relationship with brain structure in myotonic dystrophy type 1. J Neurosci Res. (2020). doi: 10.1002/jnr.24595. [Epub ahead of print].

78. Okkersen K, Buskes M, Groenewoud J, Kessels RP, Knoop H, van Engelen B, et al. The cognitive profile of myotonic dystrophy type 1: a systematic review and meta-analysis. Cortex. (2017) 95:143-55. doi: 10.1016/j.cortex.2017.08.008

79. Wozniak JR, Mueller BA, Lim KO, Hemmy LS, Day JW. Tractography reveals diffuse white matter abnormalities in Myotonic Dystrophy Type 1. J Neurol Sci. (2014) 341:73-8. doi: 10.1016/j.jns.2014.04.005

80. Goossens E, Steyaert J, De CDS, Willekens D, Fryns JP. Emotional and behavioral profile and child psychiatric diagnosis in the childhood type of myotonic dystrophy. Genetic Couns. (2000) 11:317-27.

81. Cohen D, Plaza M, Angeard N, Lanthier-Gazzano O, Baraud P, Rivière JP, et al. Reading and spelling impairments in children and adolescents with infantile myotonic dystrophy. J Neuroling. (2006) 19:455-65. doi: 10.1016/j.jneuroling.2006.03.007

82. Echenne B, Rideau A, Roubertie A, Sébire G, Rivier F, Lemieux B. Myotonic dystrophy type I in childhood: long-term evolution in patients surviving the neonatal period. Eur J Paediatr Neurol. (2008) 12:21023. doi: 10.1016/j.ejpn.2007.07.014

83. Angeard N, Gargiulo M, Jacquette A, Radvanyi H, Eymard B, Héron D. Cognitive profile in childhood myotonic dystrophy type 1: is there a global impairment? Neuromuscul Disord. (2007) 17:451-8. doi: 10.1016/j.nmd.2007.02.012

84. Woo J, Lee HW, Park JS. Differences in the pattern of cognitive impairments between juvenile and adult onset myotonic dystrophy type 1. J Clin Neurosci. (2019) 68:92-6. doi: 10.1016/j.jocn.2019.07.029

85. Modoni A, Silvestri G, Grazia Pomponi M, Mangiola F, Tonali PA, Marra C. Characterization of the pattern of cognitive impairment in myotonic dystrophy type 1. Arch Neurol. (2004) 61:1943-7. doi: 10.1001/archneur.61.12.1943

86. Callus E, Bertoldo EG, Beretta M, Boveri S, Cardani R, Fossati $\mathrm{B}$, et al. Neuropsychological and psychological functioning aspects in Myotonic Dystrophy Type 1 patients in Italy. Front Neurol. (2018) 9:751. doi: 10.3389/fneur.2018.00751

87. Censori B, Danni M, Del Pesce M, Provinciali L. Neuropsychological profile in myotonic dystrophy. J Neurol. (1990) 237:251-6. doi: 10.1007/BF00314629

88. Rakocevic-Stojanovic V, Peric S, Madzarevic R, Dobricic V, Ralic V, Ilic V, et al. Significant impact of behavioral and cognitive impairment on quality of life in patients with myotonic dystrophy type 1. Clin Neurol Neurosurg. (2014) 126:76-81. doi: 10.1016/j.clineuro.2014.08.021

89. Hamilton MJ, McLean J, Cumming S, Ballantyne B, McGhie J, Jampana $\mathrm{R}$, et al. Outcome measures for cen- tral nervous system evaluation in myotonic dystrophy type 1 may be confounded by deficits in motor function or insight. Front Neurol. (2018) 9:780. doi: 10.3389/fneur.201 8.00780

90. Jean S, Richer L, Laberge L, Mathieu J. Comparisons of intellectual capacities between mild and classic adult-onset phenotypes of myotonic dystrophy type 1 (DM1). Orphanet J Rare Dis. (2014) 9:186. doi: 10.1186/s13023-0140186-5

91. Cabada T, Iridoy M, Jericó I, Lecumberri P, Seijas R, Gargallo A, et al. Brain involvement in myotonic dystrophy type 1: a morphometric and diffusion tensor imaging study with neuropsychological correlation. Arch Clin Neuropsychol. (2017) 32:401-12. doi: 10.1093/arclin/acx008 
92. Fujino H, Shingaki H, Suwazono S, Ueda Y, Wada C, Nakayama T, et al. Cognitive impairment and quality of life in patients with myotonic dystrophy type 1. Muscle Nerve. (2018) 57:742-8. doi: 10.1002/mus.26022

93. Bird TD, Follett C, Griep E. Cognitive and personality function in myotonic muscular dystrophy. J Neurol Neurosurg Psychiatry. (1983) 46:97180. doi: 10.1136/jnnp.46.11.971

94. Minnerop M, Gliem C, Kornblum C. Current progress in CNS imaging of myotonic dystrophy. Front Neurol. (2018) 9:646. doi: 10.3389/fneur.2018.00646

95. Caliandro P, Silvestri G, Padua L, Bianchi ML, Simbolotti C, Russo G, et al. fNIRS evaluation during a phonemic verbal task reveals prefrontal hypometabolism in patients affected by myotonic dystrophy type 1. Clin Neurophysiol. (2013) 124:2269-76. doi: 10.1016/j.clinph.2013.05.010

96. Gourdon G, Meola G. Myotonic dystrophies: State of the art of new therapeutic developments for the CNS. Front Cell Neurosci. (2017) 11:114. doi: $10.3389 /$ fncel.2017.00101

97. Laberge L, Bégin P, Montplaisir J, Mathieu J. Sleep complaints in patients with myotonic dystrophy. J Sleep Res. (2004) 13:95-100. doi: 10.1111/j.1365-2869.2004.00385.x

98. Gagnon C, Mathieu J, Jean S, Laberge L, Perron M, Veillette S, et al. Predictors of disrupted social participation in myotonic dystrophy type 1 . Arch Phys Med Rehabil. (2008) 89:1246-55. doi: 10.1016/j.apmr.2007.10.049

99. Gallais B, Montreuil M, Gargiulo M, Eymard B, Gagnon C, Laberge L. Prevalence and correlates of apathy in myotonic dystrophy type 1 . BMC Neurol. (2015) 15:148. doi: 10.1186/s12883-015-0401-6

100. Laberge L, Mathieu J, Auclair J, Gagnon É, Noreau L, Gagnon C. Clinical, psychosocial, and central correlates of quality of life in myotonic dystrophy type 1 patients. Eur Neurol. (2013) 70:308-15. doi: 10.1159/000353991

101. Laberge L, Veillette S, Mathieu J, Auclair J, Perron M. The correlation of CTG repeat length with material and social deprivation in myotonic dystrophy. Clin Genet. (2007) 71:59-66. doi: 10.1111/j.1399-0004.2007.00732.x

102. Steinert H. Myopathologische Beiträge. Dtsch Z Nervenheilk. (1909) 37:58104. doi: 10.1007/BF01671719

103. Delaporte C. Personality patterns in patients with myotonic dystrophy. Arch Neurol. (1998) 55:635-40. doi: 10.1001/archneur.55.5.635

104. Antonini GMD, Federica Soscia MD, Franco Giubilei MD. Health-related quality of life in myotonic dystrophy type 1 and its relationship with cognitive and emotional functioning. J Rehabil Med. (2006) 38:1815. doi: 10.1080/16501970500477967

105. Douniol M, Jacquette A, Guilé JM, Tanguy ML, Angeard N, Héron D, et al. Psychiatric and cognitive phenotype in children and adolescents with myotonic dystrophy. Eur Child Adolesc Psychiatry. (2009) 18:70515. doi: 10.1007/s00787-009-0037-4

106. Ho G, Carey KA, Cardamone M, Farrar MA. Myotonic dystrophy type 1: clinical manifestations in children and adolescents. Arch Dis Childhood. (2019) 104:48-52. doi: 10.1136/archdischild-2018-314837

107. Sistiaga A, Urreta I, Jodar M, Cobo AM, Emparanza J, Otaegui D, et al. Cognitive/personality pattern and triplet expansion size in adult myotonic dystrophy type 1 (DM1): CTG repeats, cognition and personality in DM1. Psychol Med. (2010) 40:487-95. doi: 10.1017/S0033291709990602

108. Palmer BW, Boone KB, Chang L, Lee A, Black S. Cognitive deficits and personality patterns in maternally versus paternally inherited myotonic dystrophy. J Clin Exp Neuropsychol. (1994) 16:784-95. doi: 10.1080/01688639408402692

109. Peric S, Stojanovic VR, Basta I, Peric M, Milicev M, Pavlovic S, et al. Influence of multisystemic affection on health-related quality of life in patients with myotonic dystrophy type 1. Clin Neurol Neurosurg. (2013) 115:270-5. doi: 10.1016/j.clineuro.2012.05.015

110. Serra L, Silvestri G, Petrucci A, Basile B, Masciullo M, Makovac E, et al. Abnormal functional brain connectivity and personality traits in myotonic dystrophy type 1. JAMA Neurol. (2014) 71:603-11. doi: 10.1001/jamaneurol.2014.130

111. Paunic T, Peric S, Parojcic A, Savic-Pavicevic D, Vujnic M, Pesovic J, et al. Personality traits in patients with myotonic dystrophy type 2. Acta Myol. (2017) 36:14.

112. Huang Y, Kotov R, De Girolamo G, Preti A, Angermeyer M, Benjet C, et al. DSM-IV personality disorders in the WHO World Mental Health Surveys. Br J Psychiatry. (2009) 195:46-53. doi: 10.1192/bjp.bp.108.058552
113. Winblad S, Hellström P, Lindberg C, Hansen S. Facial emotion recognition in myotonic dystrophy type 1 correlates with CTG repeat expansion. J Neurol Neurosurg Psychiatry. (2006) 77:219-23. doi: 10.1136/jnnp.2005.070763

114. Takeda A, Kobayakawa M, Suzuki A, Tsuruya N, Kawamura M. Lowered sensitivity to facial emotions in myotonic dystrophy type 1. J Neurol Sci. (2009) 280:35-9. doi: 10.1016/j.jns.2009.01.014

115. Kobayakawa M, Tsuruya N, Takeda A, Suzuki A, Kawamura M. Facial emotion recognition and cerebral white matter lesions in myotonic dystrophy type 1. J Neurol Sci. (2010) 290:48-51. doi: 10.1016/j.jns.2009.11.011

116. Kobayakawa M, Tsuruya N, Kawamura M. Theory of mind impairment in adult-onset myotonic dystrophy type 1. Neurosci Res. (2012) 72:3416. doi: 10.1016/j.neures.2012.01.005

117. Serra L, Cercignani M, Bruschini M, Cipolotti L, Mancini M, Silvestri $\mathrm{G}$, et al. "I know that you know that I know": neural substrates associated with social cognition deficits in DM1 patients. PLoS ONE. (2016) 11:e0156901. doi: 10.1371/journal.pone.0156901

118. Shamay-Tsoory SG, Aharon-Peretz J. Dissociable prefrontal networks for cognitive and affective theory of mind: a lesion study. Neuropsychologia. (2007) 45:3054-67. doi: 10.1016/j.neuropsychologia.2007.05.021

119. Labayru G, Arenzana I, Aliri J, Zulaica M, de Munain AL. Social cognition in myotonic dystrophy type 1: specific or secondary impairment? PLoS ONE. (2018) 13:e0204227. doi: 10.1371/journal.pone.0204227

120. Serra L, Bianchi G, Bruschini M, Giulietti G, Domenico CD, Bonarota $\mathrm{S}$, et al. Abnormal cortical thickness is associated with deficits in social cognition in patients with myotonic dystrophy type 1. Front Neurol. (2020) 11:113. doi: 10.3389/fneur.2020.00113

121. Modoni A, Silvestri G, Vita MG, Quaranta D, Tonali PA, Marra C. Cognitive impairment in myotonic dystrophy type 1 (DM1). J Neurol. (2008) 255:173742. doi: 10.1007/s00415-008-0017-5

122. Bora E, Velakoulis D, Walterfang M. Meta-analysis of facial emotion recognition in behavioral variant frontotemporal dementia: comparison with Alzheimer disease and healthy controls. J Geriatr Psychiatry Neurol. (2016) 29:205-11. doi: 10.1177/0891988716640375

123. Goodkind MS, Sturm VE, Ascher EA, Shdo SM, Miller BL, Rankin KP, et al. Emotion recognition in frontotemporal dementia and Alzheimer's disease: a new film-based assessment. Emotion. (2015) 15:416. doi: 10.1037/a0039261

124. Oyamada R, Hayashi M, Katoh Y, Tsuchiya K, Mizutani T, Tominaga $\mathrm{I}$, et al. Neurofibrillary tangles and deposition of oxidative products in the brain in cases of myotonic dystrophy. Neuropathology. (2006) 26:10714. doi: 10.1111/j.1440-1789.2006.00662.x

125. Bosco G, Diamanti S, Meola G, Angeard N, Bassez G, Ekström AB, et al. Workshop report: consensus on biomarkers of cerebral involvement in myotonic dystrophy, 2-3 December 2014, Milan, Italy. Neuromusc Disord. (2015) 25:813-23. doi: 10.1016/j.nmd.2015.07.016

126. Butti C, Santos M, Uppal N, Hof PR. Von economo neurons: clinical and evolutionary perspectives. Cortex. (2013) 49:312-26. doi: 10.1016/j.cortex.2011.10.004

127. Serra L, Scocchia M, Meola G, D’Amelio M, Bruschini M, Silvestri $\mathrm{G}$, et al. Ventral tegmental area dysfunction affects decision-making in patients with myotonic dystrophy type-1. Cortex. (2020) 128:192-202. doi: 10.1016/j.cortex.2020.03.022

128. Fleming SM, Dolan RJ. The neural basis of metacognitive ability. Philos Trans R Soc B Biol Sci. (2012) 367:1338-49. doi: 10.1098/rstb.2011.0417

129. Prigatano GP, (editor). The Study of Anosognosia. Oxford University Press (2010).

130. van der Velden BG, Okkersen K, Kessels RP, Groenewoud J, van Engelen B, Knoop H, et al. Affective symptoms and apathy in myotonic dystrophy type 1 a systematic review and meta-analysis. J Affect Dis. (2019) 250:260-9. doi: 10.1016/j.jad.2019.03.036

131. Kalkman JS, Schillings ML, Zwarts MJ, Van Engelen BGM, Bleijenberg G. Psychiatric disorders appear equally in patients with myotonic dystrophy, facioscapulohumeral dystrophy, and hereditary motor and sensory neuropathy type I. Acta Neurol Scand. (2007) 115:265-70. doi: 10.1111/j.1600-0404.2006.00737.x

132. Peric S, Rakocevic-Stojanovic V, Stevic Z, Basta I, Pavlovic S, Vujanac V, et al. Health-related quality of life in patients with myotonic dystrophy type 1 and amyotrophic lateral sclerosis. Acta Neurol Bel. (2010) 110:71. 
133. Schmahmann JD. The role of the cerebellum in cognition and emotion: personal reflections since 1982 on the dysmetria of thought hypothesis, and its historical evolution from theory to therapy. Neuropsychol Rev. (2010) 20:236-60. doi: 10.1007/s11065-010-9142-x

134. Rubinsztein JS, Rubinsztein DC, Goodburn S, Holland AJ. Apathy and hypersomnia are common features of myotonic dystrophy. J Neurol Neurosurg Psychiatry. (1998) 64:510-5. doi: 10.1136/jnnp.64.4.510

135. Wansink DG, Gourdon G, van Engelen BG, Schoser B. 248th ENMC international workshop: Myotonic dystrophies: molecular approaches for clinical purposes, framing a European molecular research network Hoofddorp, The Netherlands, 11-13 October 2019. Neuromusc Disord. (2020) 30:521-31. doi: 10.1016/j.nmd.2020.03.011

136. Axford MM, Pearson CE. Illuminating CNS and cognitive issues in myotonic dystrophy: Workshop report. Neuromusc Disord. (2013) 23:3704. doi: 10.1016/j.nmd.2013.01.003

137. Bugiardini E, Meola G, Alvarez C, Angeard N, Bassez G, Bugiardini E, et al. Consensus on cerebral involvement in myotonic dystrophy. Workshop report: May 24-27. 2013, Ferrere (AT), Italy. Neuromusc Disord. (2014) 24:445-52. doi: 10.1016/j.nmd.2014.01.013

138. Franzese A, Antonini G, Iannelli M, Leardi MG, Spada S, Vichi $\mathrm{R}$, et al. Intellectual functions and personality in subjects with noncongenital myotonic muscular dystrophy. Psychol Rep. (1991) 68:723-32. doi: 10.2466/pr0.1991.68.3.723

139. Kalkman JS, Schillings ML, Zwarts MJ, van Engelen BG, Bleijenberg G. The development of a model of fatigue in neuromuscular disorders: a longitudinal study. $J$ Psychosom Res. (2007) 62:571-9. doi: 10.1016/j.jpsychores.2006.11.014

140. Bertrand JA, Jean S, Laberge L, Gagnon C, Mathieu J, Gagnon JF, et al. Psychological characteristics of patients with myotonic dystrophy type 1 . Acta Neurol Scand. (2015) 132:49-58. doi: 10.1111/ane.12356

141. Vincent KA, Carr AJ, Walburn J, Scott DL, Rose MR. Construction and validation of a quality of life questionnaire for neuromuscular disease (INQoL). Neurology. (2007) 68:1051-7. doi: 10.1212/01.wnl.0000257819.47628.41

142. Ben-Sadoun G, Sacco G, Manera V, Bourgeois J, Konig A, Foulon P, et al. Physical and cognitive stimulation using an exergame in subjects with normal aging, mild and moderate cognitive impairment. J Alzheimers Dis. (2016) 53:1299-314. doi: 10.3233/JAD-160268

143. Tong T, Chignell M, DeGuzman CA. Using a serious game to measure executive functioning: response inhibition ability. Appl Neuropsychol Adult. (2019). doi: 10.1080/23279095.2019.1683561. [Epub ahead of print].

144. Ota M, Sato N, Ohya Y, Aoki Y, Mizukami K, Mori T, et al. Relationship between diffusion tensor imaging and brain morphology in patients with myotonic dystrophy. Neurosci Lett. (2006) 407:2349. doi: 10.1016/j.neulet.2006.08.077

145. Antonini G, Mainero C, Romano A, Giubilei F, Ceschin V, Gragnani F, et al. Cerebral atrophy in myotonic dystrophy: a voxel based morphometric study. J Neurol Neurosurg Psychiatry. (2004) 75:16113. doi: $10.1136 /$ jnnp.2003.032417
146. Vielhaber S, Jakubiczka S, Gaul C, Schoenfeld MA, Debska-Vielhaber G, Zierz S, et al. Brain $1 \mathrm{H}$ magnetic resonance spectroscopic differences in myotonic dystrophy type 2 and type 1. Muscle Nerve. (2006) 34:14552. doi: 10.1002/mus.20565

147. Gagnon C, Meola G, Hébert LJ, Puymirat J, Laberge L, Leone M. Report of the first outcome measures in myotonic dystrophy type 1 (OMMYD-1) international workshop: Clearwater, Florida, November 30, 2011. Neuromusc Disord. (2013) 23:1056-68. doi: 10.1016/j.nmd.2013.07.004

148. Gagnon C, Heatwole C, Hébert LJ, Hogrel JY, Laberge L, Leone M, et al. Report of the third outcome measures in myotonic dystrophy type 1 (OMMYD-3) international workshop Paris, France, June 8, 2015. J Neuromusc Dis. (2018) 5:523-37. doi: 10.3233/JND-180329

149. Hermans MC, Hoeijmakers JG, Faber CG, Merkies IS. Reconstructing the Rasch-built myotonic dystrophy type 1 activity and participation scale. PLoS ONE. (2015) 10:e0139944. doi: 10.1371/journal.pone.01 39944

150. Hermans MC, Merkies IS, Laberge L, Blom EW, Tennant A, Faber CG. Fatigue and daytime sleepiness scale in myotonic dystrophy type 1. Muscle Nerve. (2013) 47:89-95. doi: 10.1002/mus.23478

151. Okkersen K, Jimenez-Moreno C, Wenninger S, Daidj F, Glennon J, Cumming S, et al. Cognitive behavioural therapy with optional graded exercise therapy in patients with severe fatigue with myotonic dystrophy type 1: a multicentre, single-blind, randomised trial. Lancet Neurol. (2018) 17:671-80. doi: 10.1016/S1474-4422(18)30203-5

152. Heatwole C, Bode R, Johnson N, Dekdebrun J, Dilek N, Heatwole M, et al. Myotonic Dystrophy Health Index: initial evaluation of a disease-specific outcome measure. Muscle Nerve. (2014) 49:906-14. doi: 10.1002/mus. 24097

153. Levine B, Schweizer TA, O'Connor C, Turner G, Gillingham S, Stuss DT, et al. Rehabilitation of executive functioning in patients with frontal lobe brain damage with goal management training. Front Hum Neurosci. (2011) 5:9. doi: 10.3389/fnhum.2011.00009

154. Wood L, Bassez G, van Engelen B, Lochmüller H, Schoser B, 222nd ENMC workshop participants. 222nd ENMC International Workshop:: Myotonic dystrophy, developing a European consortium for care and therapy, Naarden, The Netherlands, 1-2 July 2016. Neuromuscul Disord. (2018) 28:463-9. doi: 10.1016/j.nmd.2018.02.003

Conflict of Interest: The authors declare that the research was conducted in the absence of any commercial or financial relationships that could be construed as a potential conflict of interest.

Copyright $\odot 2020$ Simoncini, Spadoni, Lai, Santoni, Angelini, Ricci and Siciliano. This is an open-access article distributed under the terms of the Creative Commons Attribution License (CC BY). The use, distribution or reproduction in other forums is permitted, provided the original author(s) and the copyright owner(s) are credited and that the original publication in this journal is cited, in accordance with accepted academic practice. No use, distribution or reproduction is permitted which does not comply with these terms. 